\title{
Long-term storage effect on chemical composition, nutritional value and quality of Greek onion landrace "Vatikiotiko"
}

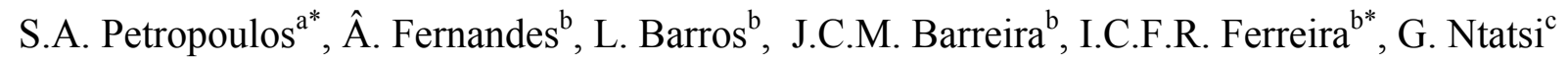

${ }^{a}$ University of Thessaly, Department of Agriculture, Crop Production and Rural Environment, 38446 N. Ionia, Magnissia, Greece.

${ }^{\mathrm{b}}$ Mountain Research Centre (CIMO), ESA, Polytechnic Institute of Bragança, Campus de Santa Apolónia, 1172, 5301-855 Bragança, Portugal.

${ }^{\mathrm{c}}$ Agricultural University of Athens, Department of Crop Production, Iera odos 75, 11855 Athens, Greece.

*Address correspondence to: Spyridon A. Petropoulos, University of Thessaly, School of Agricultural Sciences, Fytokou Street, 38446, N. Ionia, Magnissia, Greece. Email address: fangio57gr@gmail.com; and Isabel C.F.R. Ferreira, Polytechnic Institute of Bragança, Campus de Santa Apolónia, 1172, 5301-855 Bragança, Portugal. Email address: iferreira@ipb.pt

\begin{abstract}
In the present study we examined the effect of storage at two temperatures $\left(5 \pm 1\right.$ and $25 \pm 1{ }^{\circ} \mathrm{C}$ and $60-70 \pm 5 \% \mathrm{RH}$ for both temperatures) on marketability and quality features of dry bulbs of local landrace "Vatikiotiko", "Sivan F1", "Red Cross F1" and "Creamgold". The quality features recorded during storage included fresh and dry weight of bulbs, color of tunic and flesh, firmness of bulbs, nutritional value and mineral composition. The measurements were taken at regular intervals and the storage was completed when either bulbs had not marketable quality or sprouting occurred. The results have shown that "Vatikiotiko" onion can be stored for at least 7 months at $25 \pm 1{ }^{\circ} \mathrm{C}$, whereas at $5 \pm 1{ }^{\circ} \mathrm{C}$ storage could be prolonged for more than 7 months without significant marketability and quality loss. The fact that "Vatikiotiko" landrace can be considered a "storage" onion has to be capitalized in order to increase total production and yield, since storage could cover the market needs that arise throughout the year.
\end{abstract}




\section{Introduction}

Onion (Allium cepa L.) is one of the most important vegetable crops with a world annual production of 84.308 .184 tons of dry bulbs and 6.772 .128 tons of them marketed worldwide (FAO, 2011). In order to cover the market needs for dry bulbs throughout the year, a substantial amount of fresh produce has to be kept in storage rooms before marketing at retail stores. However, the quality of dry onion bulbs after long-term storage is of high importance for consumer acceptance and many factors have to be taken under consideration for optimum quality, such as genotype, and pre-harvest and post-harvest conditions. In general, short day cultivars with low content of dry matter are less susceptible to long-term storage than long day cultivars with high dry matter content (Gubb and MacTavish, 2002). Curing method (field curing or forced air curing) as well as growing conditions and harvest stage can be of major importance for obtaining dry bulbs of maximum quality (Kumar et al., 2007; Sharma et al., 2007; Coolong and Randle, 2008; Downes et al., 2009; Forney et al., 2010; Rattin et al., 2011; Thangasamy et al., 2013; Eshel et al. 2014), whereas post-harvest handling (storage temperature and relative humidity) is essential for retaining high quality till the product reaches the consumer (Gubb and MacTavish, 2002; Brewster, 2008).

Quality of onion bulbs during storage is highly affected by water losses, sprouting and rooting incidences and changes in chemical composition. Adamicki (2005) reported that storage conditions are essential for controlling sprouting, rooting and transpiration rate thus prolonging shelf-life of onion bulbs, whereas curing duration at field or via forced air drying and curing temperature, can affect root growth and quality of bulbs under storage (Downes et al., 2009; Baloch et al., 2012; Eshel et al., 2014). Moreover, according to Grevsen and Sorensen (2004) genotype and pre-harvest conditions such as transplantation instead of direct sowing and early harvest (at 20-50\% "top fall down") can reduce sprouting incidence after long-term storage. Regarding chemical composition during storage, many changes have been reported so far. 
Abayomi and Terry (2008) reported significant differences in glucose and pyruvate content of dry onion bulbs under controlled atmosphere storage, which were dependent on both the analysed cultivar and bulb section (top, middle and bottom section or outer, middle or central part). Sharma et al. (2014) reported significant changes in flavonols and sugars content during long-term storage at different light regimes (dark room and glasshouse storage), whereas amino acids content remained unaffected (Hansen, 2001). Similarly, pungency, flavor and sugar content of dry onion bulbs remained unaffected when they were stored under controlled atmospheres, whereas storage at $5{ }^{\circ} \mathrm{C}$, controlled atmospheres or field conditions increased pungency, $\mathrm{pH}$ and flavonols, and decreased soluble solids content and bulb firmness (Chope et al., 2006; Coolong et al., 2008; Rodrigues et al., 2010a; Yoo et al., 2012). In contrast, Melo et al. (2012) reported that storage of onion bulbs of cv 'Optima' at $5 \pm 1{ }^{\circ} \mathrm{C}$ and $85 \pm 5 \% \mathrm{RH}$ (relative humidity) resulted in an increase of bulb firmness after a period of 60 days.

Other compounds such as quercetin glycosides were not significantly affected by storage, however the fact that these compounds are present mostly at the outer scales which are mostly affected by drying and ageing, and usually discarded after the peeling of bulbs, can affect nutritional value and their consumption on a daily basis (Mogren et al., 2007; Grzelak et al., 2009; Cools et al., 2010; Lee and Mitchell, 2011; Yoo et al. 2013). In contrast, Olsson et al. (2010), reported that quercetin and isorhamnetin content increased during storage regardless of curing method prior to storage. Flavonols content also increased after long-term storage either under field conditions or under refrigeration (increase by 40 and 64\% respectively) (Rodrigues et al., 2010b).

Carbohydrate content is significantly decreased during storage, mostly due to increased respiration, which consequently resulted in higher nitrogen and protein content in the dry matter (Hansen, 1999). In addition, sugar composition depended on storage duration and temperature and was strongly correlated with the end of dormant state and sprouting initiation 
since sucrose and fructo-oligosaccharide hydrolysis by metabolizing enzymes seemed to act as a biochemical signal for sprouting by increasing the levels of fructose due to fructans hydrolysis (Jaime et al., 2001; Benkeblia et al., 2004; Benkeblia et al., 2005a,b).

The aim of the present study was to evaluate for the first time the effect of two storage conditions that are commercially applied for onion storage on quality features and marketability of local landrace "Vatikiotiko" in comparison with three commercial genotypes. For this reason, dry onion bulbs were stored at $5 \pm 1$ and $25 \pm 1{ }^{\circ} \mathrm{C}$ and $60-70 \pm 5 \% \mathrm{RH}$ for both temperatures and water loss, bulb quality features, nutritional value and chemical composition of bulbs were evaluated.

\section{Materials and Methods}

\subsection{Sampling}

Onions (30 kg of dry onion bulbs) produced in Lakonia prefecture ("Vatikiotiko" and "Sivan F1', latitude $36^{\circ} 31^{\prime} 42^{\prime \prime}$, longitude $23^{\circ} 02^{\prime} 51^{\prime \prime}, 10$ meters above the sea level) and the region of Thebes (“Red Cross F1", latitude $38^{\circ} 19^{\prime} 39^{\prime \prime}$, longitude $23^{\circ} 19^{\prime} 04^{\prime \prime}, 120$ m above sea level) were collected within the first fortnight of June 2014 (10-15 ${ }^{\text {th }}$ of June), from farmers directly after field curing for 2 weeks and when ready for marketing. In addition, bulbs of "Creamgold" onion were purchased from a retail supermarket in net bags of $1 \mathrm{~kg}$ and 50-70 $\mathrm{mm}$ diameter grading on June 15, 2014. "Vatikiotiko", "Sivan F1" and "Red Cross F1" were short day onions, whereas "Creamgold" was a long-day onion. After sample collection an assessment of quality features was carried out on June 18, 2014 ( $\mathrm{t} 0$ : first measurement) and then samples from each genotype were stored at two different conditions.

\subsection{Storage conditions}


Storage conditions were as follows: a) $5 \pm 1{ }^{\circ} \mathrm{C}$ and $65-70 \pm 5 \%$ Relative Humidity (RH), and b) $25 \pm 1{ }^{\circ} \mathrm{C}$ and $65-70 \pm 5 \%$ Relative Humidity $(\mathrm{RH})$. During storage, all the bulbs were recorded for their weight at regular intervals (approximately every 30 days), whereas quality features were recorded twice after the initial measurement ( $\mathrm{t} 1$ and $\mathrm{t} 2 \mathrm{samples})$. The first measurement was carried out 126 days after storage, and the second and final measurement was carried out 139 to 210 days after storage (depending on storage conditions and genotype). The last measurement for each genotypes was taken when bulbs started to sprout or when marketable quality of bulbs was unacceptable (severe water losses and very low visual appearance). In the case of "Red Cross F1" only two measurements were taken for the storage temperature of 25 ${ }^{\circ} \mathrm{C}$ due to early sprouting.

\subsection{Bulb quality features}

Quality assessment was carried out as previously described by Petropoulos et al. (2015). The recorded features were fresh and dry weight, color of tunic and flesh and total soluble solids ( $\left.{ }^{\circ} \mathrm{Brix}\right), \mathrm{pH}$ and electrical conductivity (EC) of edible flesh. TSS content was measured with hand-held refractometer TR53000C (T.R. Turoni SRL, Italy) on juice taken from the edible scales (Carl Zeiss Jena, Germany). Bulb firmness was recorded with a flat bottom probe (d=9 $\mathrm{mm}$ and $9 \mathrm{~mm}$ width) using digital fruit firmness tester TR53205 (T.R. Turoni, SRL, Italy) and applied to the equatorial axis at three different points. Color measurements were carried out with the implementation of Chroma Meter CR-400 (Konica Minolta Inc., Tokyo, Japan) using the CIELAB co-ordinate system $(\mathrm{L}, \mathrm{a}, \mathrm{b})$, whereas Chroma values $\left(\mathrm{C}^{*}\right)$ which according to McGuire (1992) describes color saturation and hue angle $\left(\mathrm{h}^{*}\right)$ which describes color shadiness $\left(0^{\circ}=\right.$ red-purple, $90^{\circ}=$ yellow, $180^{\circ}=$ bluish-green and $270^{\circ}=$ blue $)$, were determined according the following formulas:

$$
C^{*}=\sqrt{a^{* 2}+b^{* 2}}
$$




$$
\begin{aligned}
& h^{*}=180+\left(\frac{\left(\arctan \frac{b^{*}}{a^{*}}\right)}{6.2832}\right) * 360, \text { when } a^{*}<0 \text { and } \\
& h^{*}=\left(\frac{\left(\arctan \frac{b^{*}}{a^{*}}\right)}{6.2832}\right) * 360, \text { when } a^{*}>0 .
\end{aligned}
$$

For color differences during storage the Total Color Difference $(\Delta \mathrm{E})$ was calculated according to the formula proposed by Goyeneche et al. (2014):

$$
\Delta E=\sqrt{\left(a_{\text {final }}-a_{\text {initial }}\right)^{2}+\left(b_{\text {final }}-b_{\text {initial }}\right)^{2}+\left(L_{\text {final }}-L_{\text {initial }}\right)^{2}}
$$

According to Chen and Mujumbar (2008) $\Delta \mathrm{E}$ values within the range of 0-0.5 indicate trace color differences, $\Delta \mathrm{E}=0.5-1.5$ slight color differences, $\Delta \mathrm{E}=1.5-3.0$ noticeable color differences, $\Delta \mathrm{E}=3.0-6.0$ appreciable color differences, $\Delta \mathrm{E}=6.0-12.0$ large color differences, and $\Delta \mathrm{E}>12.0$ very obvious color differences.

Titratable acidity was calculated as $\mathrm{g}$ malic acid/100 $\mathrm{mL}$ of juice, after titration with $0.1 \mathrm{~N}$ $\mathrm{NaOH}$ to an endpoint of $\mathrm{pH}$ 8.2. Three samples per genotype were analyzed and their mean value was used for statistical analysis.

\subsection{Nutritional value and chemical composition}

For chemical composition sampling, onion bulbs were bisected equatorially in order to obtain a section of about $1 \mathrm{~cm}$ height and $10 \mathrm{~g}$ of fresh weight and after removing the outer skin the flesh was cut in small pieces. Samples were taken from 15 bulbs (150 g of fresh weight in total) from each genotype and all the samples were pulled in one and stored at deep freezing conditions $\left(-80^{\circ} \mathrm{C}\right)$ and freeze dried prior to analysis. The freeze dried samples were powdered with pestle and mortar and divided in three samples for further analysis.

The samples were analysed for proteins, fat, carbohydrates and ash using the AOAC (1995) procedures. The crude protein content $(\mathrm{N} \times 6.25)$ of the samples was estimated by the macroKjeldahl method; the crude fat was determined by extracting a known weight of powdered 
sample with petroleum ether, using a Soxhlet apparatus; the ash content was determined by incineration at $600 \pm 15^{\circ} \mathrm{C}$. Total carbohydrates were calculated by difference. Energy was calculated according to the following equation: Energy $(\mathrm{kcal})=4 \times(\mathrm{g}$ protein $)+4 \times(\mathrm{g}$ carbohydrate $)+9 \times($ g fat $)$

For mineral composition samples of dry bulbs tissues were dried in a forced-air oven at $72^{\circ} \mathrm{C}$ to constant weight, ground to powder, subjected to dry ashing and extracted with $1 \mathrm{~N} \mathrm{HCl}$ to determine the mineral. $\mathrm{Ca}, \mathrm{Mg}, \mathrm{Fe}, \mathrm{Mn}, \mathrm{Zn}$, and $\mathrm{Cu}$ content were determined by atomic absorption spectrophotometry (Perkin Elmer 1100B, Waltham, MA) and Na and K content by flame photometry (Sherwood Model 410, Cambridge, UK).

Organic acids were determined following a procedure previously optimized by the authors (Pereira, Barros, Carvalho \& Ferreira, 2013). The analysis was performed using a Shimadzu 20A series UFLC (Shimadzu Cooperation, Kyoto, Japan). Separation was achieved on a SphereClone (Phenomenex, Torrance, CA, USA) reverse phase $\mathrm{C}_{18}$ column $(5 \mu \mathrm{m}, 250 \mathrm{~mm} \times$ $4.6 \mathrm{~mm}$ i.d) thermostatted at $35^{\circ} \mathrm{C}$. The elution was performed with sulphuric acid $3.6 \mathrm{mM}$ using a flow rate of $0.8 \mathrm{~mL} / \mathrm{min}$. Detection was carried out in a DAD, using $215 \mathrm{~nm}$ and 245 nm (for ascorbic acid) as preferred wavelengths. The organic acids found were quantified by comparison of the area of their peaks recorded at 215 or $245 \mathrm{~nm}$ with calibration curves obtained from commercial standards of each compound.

Free sugars were determined by high performance liquid chromatography coupled to a refraction index detector (HPLC-RI), after an extraction procedure previously described (Guimarães et al., 2013). The equipment consisted of an integrated system with a pump (Knauer, Smartline system 1000, Berlin, Germany), degasser system (Smartline manager 5000), auto-sampler (AS-2057 Jasco, Easton, MD, USA) and an RI detector (Knauer Smartline 2300, Berlin, Germany). Data were analysed using Clarity 2.4 Software (DataApex, Podohradska, Czech Republic). Sugars identification was made by comparing the relative 
retention times of sample peaks with standards and quantification was based on the RI signal response of each standard, using the internal standard (IS, melezitose) method and by using calibration curves obtained from the commercial standards of each compound.

Fatty acids were determined after a transesterification procedure as described previously by the authors (Guimarães et al., 2013). The fatty acids profile was analyzed with a DANI 1000 gas chromatographer (GC) equipped with a split/splitless injector and a flame ionization detector (FID). Fatty acid identification was made by comparing the relative retention times of FAME peaks from samples with standards. The results were recorded and processed using Clarity 4.0.1.7 Software (DataApex, Podohradska, Czech Republic).

Tocopherols were determined following a procedure previously described by the authors (Guimarães et al., 2013). Analysis was performed by HPLC (equipment described above), and a fluorescence detector (FP-2020; Jasco) programmed for excitation at $290 \mathrm{~nm}$ and emission at $330 \mathrm{~nm}$. The compounds were identified by chromatographic comparisons with authentic standards. Quantification was based on the fluorescence signal response of each standard, using the IS (tocol) method and by using calibration curves obtained from commercial standards of each compound.

\subsection{Antioxidant activity and bioactive compounds}

Antioxidant activity and bioactive compounds were assessed according to methods previously reported by Roriz et al. (2014). Methanolic/water $(80: 20, v / v)$ extracts were obtained from the lyophilized material. Each sample $(1 \mathrm{~g})$ was extracted twice by stirring $\left(25^{\circ} \mathrm{C}\right.$ at $\left.150 \mathrm{rpm}\right)$ with $30 \mathrm{~mL}$ of methanol/water $(80: 20, v / v)$ for $1 \mathrm{~h}$ and subsequently filtered through a Whatman No. 4 paper. The combined methanol/water extracts were evaporated at $40{ }^{\circ} \mathrm{C}$ (rotary evaporator Büchi R-210, Flawil, Switzerland) to remove the methanol and further frozen and lyophilized. The extracts were redissolved in methanol/water $(80: 20, v / v)$ at a final concentration of 50 
$\mathrm{mg} / \mathrm{mL}$ and further diluted to different concentrations to be submitted to the distinct in vitro assays.

DPPH radical-scavenging activity was evaluated by using an ELX800 microplate reader (BioTek Instruments, Inc; Winooski, VT, USA), and calculated as a percentage of DPPH discolouration using the formula: $\left[\left(\mathrm{A}_{\mathrm{DPPH}}-\mathrm{A}_{\mathrm{S}}\right) / \mathrm{A}_{\mathrm{DPPH}}\right] \times 100$, where $\mathrm{A}_{\mathrm{S}}$ is the absorbance of the solution containing the sample at $515 \mathrm{~nm}$, and $\mathrm{A}_{\mathrm{DPPH}}$ is the absorbance of the DPPH solution. Reducing power was evaluated by the capacity to convert $\mathrm{Fe}^{3+}$ to $\mathrm{Fe}^{2+}$, measuring the absorbance at $690 \mathrm{~nm}$ in the microplate reader mentioned above. Inhibition of $\beta$-carotene bleaching was evaluated though the $\beta$-carotene/linoleate assay; the neutralization of linoleate free radicals avoids $\beta$-carotene bleaching, which is measured by the formula: $\beta$-carotene absorbance after $2 \mathrm{~h}$ of assay/initial absorbance) $\times 100$. Lipid peroxidation inhibition in porcine (Sus scrofa) brain homogenates was evaluated by the decreasing in thiobarbituric acid reactive substances (TBARS); the colour intensity of the malondialdehyde-thiobarbituric acid (MDATBA) was measured by its absorbance at $532 \mathrm{~nm}$; the inhibition ratio (\%) was calculated using the following formula: $[(\mathrm{A}-\mathrm{B}) / \mathrm{A}] \times 100 \%$, where $\mathrm{A}$ and $\mathrm{B}$ were the absorbance of the control and the sample solution, respectively (Guimarães et al., 2013). The results were expressed in $\mathrm{EC}_{50}$ values (sample concentration providing $50 \%$ of antioxidant activity or 0.5 of absorbance in the reducing power assay) for antioxidant activity and Trolox was used as a positive control. Total phenolics were estimated by Folin-Ciocalteu colorimetric assay according to procedures previously described (Barros, Oliveira, Carvalho \& Ferreira, 2010) and the results were expressed as $\mathrm{mg}$ of gallic acid equivalents (GAE) per $\mathrm{g}$ of sample. Total flavonoids were determined by a colorimetric assay using aluminum trichloride, following procedures previously reported (Barros et al., 2010); the results were expressed as mg of (+)-catechin equivalents $(\mathrm{CE})$ per $\mathrm{g}$ of sample. 


\subsection{Statistical analysis}

For each genotype, three samples were used for each temperature and storage time; all the assays were carried out in triplicate. An analysis of variance (ANOVA) with type III sums of squares was performed using the GLM (General Linear Model) procedure of the SPSS software. The dependent variables were analyzed using 3-way ANOVA, with the factors temperature $(\mathrm{T})$, storage time $(\mathrm{ST})$ and genotype $(\mathrm{G})$. When a statistically significant interaction $(T \times S T, T \times G, S T \times G$ or $T \times S T \times G)$ was detected, the corresponding factors were evaluated simultaneously by the estimated marginal means plots for all levels of each single factor. Alternatively, if no statistical significant interaction was verified, means within each factor were compared using Tukey's honestly significant difference (HSD) multiple comparison test.

In addition, a linear discriminant analysis (LDA) was used to compare the effects of temperature (T), storage time (ST) and genotype $(\mathrm{G})$, in order to verify which parameters suffered the highest changes in each case, and also to check if the clustering patterns match the naturally occurring groups corresponding to the levels $\left(5\right.$ and $25^{\circ} \mathrm{C} ; 0$, t1 and $\mathrm{t} 2$; 'Red Cross F1', 'Sivan F1', 'Vatikiotiko' and 'Creamgold') of each factor. A stepwise technique was applied, considering the Wilks' $K$ test (to verify the significance of the canonical discriminating functions) with the usual probabilities of F (3.84 to enter and 2.71 to be removed) for variable selection. This procedure uses a combination of forward selection and backward elimination steps, where the inclusion of a new variable is preceded by verifying the significance of all previously selected variables (Zielinsky et al., 2014). The basic purpose of the discriminant analysis estimates the relationship between the single categorical dependent variables $(T, S T$ and $G$ ) and a set of quantitative independent variables (the values obtained in all the assays). Through this method, it is possible to determine which of the independent variables contributed more for the differences in the average score profiles of the onion samples. A leaving-one-out 
cross validation procedure was carried out to assess the model performance. All the statistical analysis were carried out using SPSS v. 22.0 program (IBM Corp., Armonk, NY, USA).

\section{Results and discussion}

\subsection{Bulb quality features}

Weight loss during storage differed significantly among the various genotypes as well as between the applied storage temperatures (Figure 1). In general, weight loss percentage was higher when bulbs were stored at $25^{\circ} \mathrm{C}$ comparing to storage at $5{ }^{\circ} \mathrm{C}$, with the most profound effect of storage temperature observed for 'Vatikiotiko' landrace, where weight loss was almost doubled (12.57\% and $6.65 \%$ weight loss for 25 and $5{ }^{\circ} \mathrm{C}$ respectively). However, overall quality for this genotype was not significantly affected and bulbs retained marketable quality even after 210 days of storage, regardless of storage temperature. For the other genotypes, storage temperature had a detrimental effect on storage duration, since high temperatures promoted sprouting incidence and consequently resulted in rapid water loss rates and quality degradation.

Overall, weight loss is the combination of water losses and dry matter reduction due to consumption of energy reserves. Moreover, water loss is the limiting factor for long-term storage and is highly correlated with sprouting initiation, which consequently results in higher metabolic rates and water and dry matter losses. Adamicki (2005) and Grevsen and Sorensen (2004) have also reported that storage potential of dry onion bulbs is dependent on storage conditions, whereas Gubb and MacTavish (2002) suggested that apart from storage conditions genotype could also affect storage potential. Therefore, the fact that 'Vatikiotiko' landrace has high content of dry matter allows for longer storage without significant quality degradation since according to the literature, onion genotypes with high dry matter content contain more 
fructans than genotypes with low dry matter content and are more susceptible to long-term storage (Davis et al., 2007; Petropoulos et al., 2015).

There was a significant interaction among all the factors for all the assessed bulb quality parameters, except for total soluble solids content as expressed by ${ }^{\circ}$ Brix (Table 1). Bulb firmness decreased during storage, with higher temperatures resulting in less firm bulbs and consequently in faster quality degradation, mostly due to higher water losses through the outer skin (Hole et al., 2002). Among the studied genotypes, 'Vatikiotiko' bulbs had the highest firmness prior to storage, a fact that contributed to slower quality degradation and higher storage potential comparing to the other genotypes. Previous reports have confirmed the decrease of bulb firmness during storage (Chope et al., 2006; Coolong et al., 2008; Rodrigues et al., 2010a; Yoo et al., 2012), whereas in contrast, Melo et al. (2012) reported an increase after 30 days of storage at $5{ }^{\circ} \mathrm{C}$. This difference may be due to the storage duration, since Melo et al. (2012) carried out a short-term storage comparing to longer storage periods of this study and other reports (60 days of storage comparing to 210 days in the present study).

Dry matter content reduced significantly during storage for 'Red Cross $\mathrm{F} 1$ ' at $25^{\circ} \mathrm{C}$, whereas for 'Vatikiotiko' and 'Creamgold' no significant changes were observed (Table 1). Ilić et al. (2009) have also reported a decrease in dry matter content and they also suggest that this decrease is depended on genotype. In contrast, Chope et al. $(2007 ; 2012)$ have reported that storage did not affect dry matter content suggesting that it is mostly affected by growing conditions and cultivar. These contradictory results could be explained mainly by the different response of various genotypes to long-term storage, as well as by the fact that dry matter losses are expressed as the combined result of energy reserves' consumption and water losses. Therefore, high rates of water loss could conceal losses of dry matter, considering that dry matter is expressed as the remaining of fresh weight after deducting water content. 
Dry matter content and consequently low water content are positively correlated with storage potential, since during sprouting energy reserves are consumed in order to promote shoot growth, whereas low water content inhibits metabolic processes and eventually sprouting (Rivera et al., 2005). Therefore genotypes with initial low water and high dry matter content are less susceptible to fresh weight losses during storage. Total soluble solids, titratable acidity, and juice $\mathrm{pH}$ and electrical conductivity were slightly decreased, fluctuated or remained unchanged during storage, showing no specific trend (Table 1). Similar results for total soluble solids content have also been reported by Benkeblia et al. (2002) who suggested a pattern of peaks and wells during the storage period. However, there are conflicting reports in the literature, since sugar content during storage can be affected by cultivar, storage temperature and postharvest treatments showing either a constant pattern or a fluctuating pattern (Hansen, 1999; Chope et al., 2007).

For the assessed color indices of tunic and flesh, a significant interaction among the applied factors was recorded only in the case of $\mathrm{a}$ and $\mathrm{b}$ indices of tunic and $\mathrm{C}^{*}$ and $\mathrm{h}^{*}$ values of flesh, without however specific trends in color changes being observed (data not shown). $\Delta \mathrm{E}$ values showed significant changes in color during storage, with tunic color differences being higher at $25{ }^{\circ} \mathrm{C}$ comparing to $5{ }^{\circ} \mathrm{C}$, and those of flesh being lower at the same conditions, while according to the grading proposed by Chen and Mujumbar (2008), color differences were larger for 'Sivan F1' (within the range of 6.0-12.0 for $\Delta \mathrm{E}$ values) among the tested genotypes (Figure 2). Similar results have been reported by Eshel et al. (2014) who examined the effect of curing duration on skin color after five months of storage and found no color changes in terms of hue angle values, whereas Downes et al (2009) suggested that tunic color is highly prone to changes mostly due to the effect of high temperatures during curing since the content of flavonols and anthocyanin glucosides in skin may change. 


\subsection{Nutritional value and chemical composition}

Regarding nutritional value of onion bulbs, significant changes were observed during storage for all the tested genotypes without significant differences between the applied temperatures (Table 2). Ash content increased during storage in the case of 'Vatikiotiko' and 'Creamgold', whereas protein content decreased for 'Red Cross F1' and 'Sivan F1' and increased for 'Vatikiotiko' genotype. Fat content increased for all the genotypes, except for the case of 'Red Cross $\mathrm{F} 1$ ' bulbs stored at $25^{\circ} \mathrm{C}$, while carbohydrate content showed a slight decrease for all the genotypes apart from 'Creamgold' where remained stable. To our knowledge, this is the first time that a complete nutritional profile of onion bulbs during storage is studied, with 'Vatikiotiko' genotype having the highest nutritional value among the tested genotypes after a long-term storage (210 days).

Organic acids content was also affected by storage duration and storage temperature in terms of both total organic acids content and organic acid composition, whereas the various genotypes responded differently depending on storage temperature and specific organic acids (Table 3). In particular, oxalic acid increased significantly at both temperatures, regardless of genotype, whereas citric acid decreased when onion bulbs were stored at $5^{\circ} \mathrm{C}$. In contrast, citric acid content increased when storage temperature was high $\left(25^{\circ} \mathrm{C}\right)$ for all the genotypes except for 'Red Cross F1' which storage ended earlier than the other genotypes due to sprouting. Malic and ascorbic acid have also increased in the case of 'Red Cross F1', whereas for 'Sivan F1' only ascorbic acid increased at both temperatures. Fumaric acid decreased at high temperatures for all the genotypes, except for 'Creamgold', whereas an increase of total organic acids content was observed at $25^{\circ} \mathrm{C}$. Changes in organic acids content have also been reported by Benkbelia and Varoquax (2003), who examined the effect of $\mathrm{NO}_{2}$ on onion bulb quality during storage, however their results are not comparable with those of our study due to different storage conditions $\left(18^{\circ} \mathrm{C}\right)$ and treatments $\left(\mathrm{NO}_{2}\right)$. 
Regarding total sugars content, an increase was observed during storage for all the genotypes at $5{ }^{\circ} \mathrm{C}$, apart from 'Sivan $\mathrm{F} 1$ ' where after an increase, sugar content decreased significantly at levels lower than the initial content (Table 4). At $25{ }^{\circ} \mathrm{C}$, total sugars content either increased ('Sivan F1', 'Vatikiotiko' and 'Creamgold') or slightly decreased ('Red Cross F1'). Sugar composition was affected in different ways depending on genotype, storage temperature and the individual sugars with no specific trends to be observed (Table 4). However, a significant increase was observed in sucrose content at $25^{\circ} \mathrm{C}$ for all the genotypes, as well as for glucose at $5{ }^{\circ} \mathrm{C}$ (except for 'Sivan F1' where glucose content was slightly decreased). Long-term storage had a beneficial effect especially for 'Vatikiotiko' genotype, where total sugars and fructose, glucose and sucrose content (except for the case of glucose at $25{ }^{\circ} \mathrm{C}$ ) increased significantly suggesting a positive correlation with taste and sweetness and therefore a better consumer acceptance comparing to the other genotypes. The changes in sugar composition are better explained by the ratio of monosaccharides: disaccharides (glugose+fructose: sucrose), where at low temperatures $\left(5^{\circ} \mathrm{C}\right)$ the ratio either increased or slightly decreased (in the case of 'Sivan F1') during storage, whereas at high temperatures a significant decrease was observed for all the genotypes and despite their differences in sugar profile (Figure 3).

An increase in sugar content was also observed in bulbs stored at ambient conditions $\left(20-25^{\circ} \mathrm{C}\right.$ and $60-80 \% \mathrm{RH}$ ) by Sharma et al. (2015). In addition, Benkbelia et al. (2005a,b) have reported an increase in reducing sugars after a long-term storage due to hydrolysis of fructooligosaccharides prior to sprouting initiation, whereas Abayomi and Terry (2009), Yoo et al. (2012) and Sharma et al. (2014) reported fluctuations in sucrose, fructose and glucose content during long-term storage at various conditions. Moreover, glucose content and its changing rate during long-term storage seem to be affected by the bulb part in a three-dimensional profile (Abayomi and Terry, 2009). A decrease in the ratio of monosaccharides: disaccharides was similarly observed by Chope et al. (2007), who examined the effect of controlled atmospheres 
(CA), air and their transitional combination [CA/air or air/CA] on sugar content. The same authors confirmed the differences in sugar profiles according to the genotype, as it was the case in our study. However, they found no significant effect of storage conditions on the ratio of monosaccharides: disaccharides, which could be attributed to the fact that they applied only low temperatures $\left(2{ }^{\circ} \mathrm{C}\right)$ during storage.

Storage affected mineral composition of onion bulbs, without observing differences among the studied genotypes and the applied storage temperature in most of the cases (Table 5). Potassium content increased significantly during storage, whereas $\mathrm{Ca}, \mathrm{Mg}$ and $\mathrm{Fe}$ showed a decrease. For $\mathrm{Zn}, \mathrm{Mn}$ and $\mathrm{Na}$ the response depended on genotype, with $\mathrm{Zn}$ and $\mathrm{Mn}$ showing an increase in the case of 'Vatikiotiko' and 'Creamgold' and a decrease in the case of 'Red Cross F1'. To our knowledge, so far there is scarce information available about the effect of storage duration and storage temperature on mineral composition of onion bulbs. A very important finding of our study is about the decrease rate of $\mathrm{Ca}$ content during storage, which was significantly lower in the case of 'Vatikiotiko' comparing to the other genotypes. The slower decrease rate in $\mathrm{Ca}$ content and the higher initial bulb firmness values for 'Vatikiotiko' bulbs comparing to other genotypes could explain the long-term storage potential of the specific genotype, since Ca content is positively correlated with bulb firmness, with higher firmness and higher Ca content suggesting a better storage potential (Coolong and Randle, 2008).

Fatty acids content was also affected by storage, however the response for each fatty acid differed according to the genotype and the storage temperature (Table 6). Despite these differences, for all the genotypes the main fatty acid was linoleic acid (LA, C18:2n6) which increased during storage for all the genotypes except for 'Creamgold'. Saturated fatty acids (SFA) content accounted for about $30 \%$ of total fatty acids and showed slight fluctuation during storage. Monounsaturated fatty acids (MUFA) accounted for about 15-30\% of total fatty acids before storage and showed a significant decrease during storage for all the genotypes except for 
'Creamglod' where decrease was either slight $\left(5^{\circ} \mathrm{C}\right)$ or not significant $\left(25^{\circ} \mathrm{C}\right)$. Polyunsaturated fatty acids (PUFA), which accounted for the largest part of total fatty acids showed a significant increase in most cases except for 'Creamgold' genotype. Fatty acids content in onion bulbs during storage has not been reported previously, mostly because onion is not considered a rich source for these compounds and therefore does not contribute notably in their daily intake from human. However, Petropoulos et al. (2015) have already reported the effect of genotype on fatty acids composition for the same genotypes tested in the present study.

\subsection{Antioxidant activity and bioactive compounds}

Total tocopherols content was positively affected by storage, since an increase was observed during storage for all the studied genotypes at both temperatures (data not shown). Moreover, tocopherols consist only from $\alpha$-tocopherol, whereas $\delta$-tocopherol was not detected either before or after storage. Since it is the first time that tocopherols content in relation to storage duration and storage temperature is presented, there is no available information in the literature. Total phenols content decreased significantly at both temperatures in the case of 'Sivan F1', 'Vatikiotiko' and 'Creamgold' (Table 7). In contrast, for 'Red Cross F1' an increase was observed, especially at high temperatures, which could be attributed to the limited storage duration comparing to the other genotypes. Similar trends were reported by Benkeblia et al. (2000) who studied the phenols content during storage at 4 and $20{ }^{\circ} \mathrm{C}$, arguing that there is an inverse correlation of phenolics and sprouting incidence as well as a linkage with phenylalanine amonia-lyase (PAL) enzyme activity which results in this decrease.

Flavonoids content increased significantly during storage at both temperatures, except for the case of 'Sivan F1' at $25{ }^{\circ} \mathrm{C}$ where a steep increase was followed by a decrease at the initial levels (Table 6). Similarly, Rodrigues et al. (2010a,b) have reported that long-term storage resulted in an increase of flavonols content suggesting that enzymatic activity during storage is 
responsible for that increase. Moreover, Yoo et al. (2012) observed an increase of flavonoids content at high temperatures $\left(30^{\circ} \mathrm{C}\right)$, especially in the outer scales where these compounds are present at higher concentrations.

Antioxidant activity as expressed by DPPH radical-scavenging activity and reducing power, reduced during storage at both temperatures for all the genotypes except for 'Red Cross F1' and the case of DPPH radical-scavenging activity where an increase was observed (Table 6). In addition, $\beta$-carotene bleaching inhibition reduced in most cases, as well as TBARS inhibitions which also reduced for all the studied genotypes and the applied temperatures during storage (Table 6). Similarly to our results, Gennaro et al. (2002) observed a decrease in antioxidant activity of 'Tropea Red' onion.

\subsection{Linear Discriminant Analysis}

As discussed in the previous section, it was possible to identify different statistically significant effects (either induced by ST, T or G) in some of the evaluated parameters. However, to characterize better each of levels $\left(\mathrm{T}\right.$ : $5^{\circ} \mathrm{C}$ and $25^{\circ} \mathrm{C}$; ST: 0 days, 60 days and 120; G: 'Red Cross F1', 'Sivan F1', 'Vatikiotiko' and 'Creamgold') of the assayed factors, it is important to identify which of the parameters contributed more decisively to define those levels and also if the detected differences are enough to discriminate the naturally occurring groups (i.e., the established levels). Accordingly, different linear discriminant analysis (LDA) were performed with the basic objective of evaluating the linkage between the T, ST or G levels (categorical dependent variables) and the matrix of obtained results (quantitative independent variables). The significant independent variables were selected following the stepwise method of the LDA, according to the Wilks' $\lambda$ test. Only variables with a statistically significant classification performance $(\mathrm{p}<0.050)$ were maintained by the statistical model. 
Regarding the $\mathrm{T}$ effect, the defined discriminant function included $100 \%$ of the observed variance by selecting total acidity, conductivity, fructose, sucrose, citric acid, saturated fatty acids, phenols and flavonoids as the variables with the most discriminant effect. This is a first indication of the weak effect of using different temperatures in the onions' storage. In fact, from the 55 studied parameters, only the listed 8 contributed significantly to separate the assayed T levels. Furthermore, the classification performance was not $100 \%$ accurate, since $15.2 \%$ of the " $5{ }^{\circ} \mathrm{C}$ " samples were classified as " $25{ }^{\circ} \mathrm{C}$ " and $19.4 \%$ the " $25^{\circ} \mathrm{C}$ " samples were classified as " $5{ }^{\circ} \mathrm{C}$ " for the original grouped cases, while $21.2 \%$ of the "5 ${ }^{\circ} \mathrm{C}$ " samples were classified as " $25{ }^{\circ} \mathrm{C}$ " and $22.2 \%$ the " $25{ }^{\circ} \mathrm{C}$ " samples were classified as " $5{ }^{\circ} \mathrm{C}$ " for the crossvalidated grouped cases. In a simpler analysis, the presented results indicated that the characterized profiles did not present enough differences to be correctly classified by the developed linear discriminant model. Even so, it should be noted that the variables more highly correlated with the discriminant function were citric acid, sucrose and conductivity (all higher in the " $25^{\circ} \mathrm{C}$ " samples), thereby showing that these were the most susceptible to changes in the storing temperature.

It must be emphasized that according to the literature (Gubb and MacTavish, 2002; Brewster, 2008) both implemented temperatures are considered ideal for short to medium-term onion storage, while $0-5{ }^{\circ} \mathrm{C}$ are considered the optimum temperature range for long-term storage. The fact that in our study the end of storage time differed for the various genotypes and temperatures according to their susceptibility to sprouting incidence and the overall visual appearance and marketable quality, diminishes the storage temperature effect on most of the studied variables. However, from our results and from all the tested genotypes, 'Vatikiotiko' can be considered as a long-term storage onion since it can be stored for as many as 210 days at both temperatures, whereas for all the other genotypes quality is severely affected at $25{ }^{\circ} \mathrm{C}$ earlier than $5^{\circ} \mathrm{C}$. More specifically, 'Creamgold' can also be considered a genotype suitable for 
long storage only when low temperatures are applied, since at high temperatures sprouting incidence and overall quality degradation increase significantly after 139 days of storage. 'Sivan F1' can also be stored for long periods at low temperatures (182 days), whereas at high temperatures storage period is shortened substantially (153 days). Finally, 'Red Cross F1' could be considered ideal for medium-term storage, since after 126 and 147 days quality decreases at 25 and $5{ }^{\circ} \mathrm{C}$ respectively, mostly due to early sprouting incidence.

A similar analysis was performed to evaluate the overall effect of the ST factor. In this case, two discriminant functions were defined (number of levels minus one), which also included $100 \%$ of data variance. ST exerted a more pronounced effect, since 32 of the 55 assayed variables were selected as having discriminant ability (dry matter, fat, protein, carbohydrates, all color parameters except from Chroma $\left(\mathrm{C}^{*}\right)$ and hue angle $\left(\mathrm{h}^{*}\right)$ values measured in onion tunic, ${ }^{\circ}$ Brix, trehalose, the unidentified sugar, sugars, malic acid, $\alpha$-tocopherol, C18:0, MUFA, $\mathrm{K}, \mathrm{Na}$ and $\mathrm{Zn}$ were excluded), indicating their significant differences according to the storing period. Function 1, which was mostly correlated to $\mathrm{Mg}, \mathrm{Ca}, \mathrm{Fe}$ (all higher for non-stored samples), reducing power (non-stored showed highest reducing power) and TBARS formation inhibition (which was stronger in stored samples) placed the markers corresponding to the 0 days period far from the remaining samples, proving their significant differences (Figure 4). Furthermore, the individualization of both ST ( $\mathrm{t} 1$ and $\mathrm{t} 2$ ) was mostly achieved through function 2, which was highly correlated to total acidity (higher in " $\mathrm{t} 1$ " samples), ash (higher in "t2 days" samples) and $\beta$-carotene (lower activity in "t2 days" samples). In this case, all samples were correctly classified, either for original group cases, as well as for cross-validated cases. These results clearly show the effect of storage duration on quality parameters and chemical composition of onion during storage, as already has been reported by Adamicky (2005), Brewster (2008), Gubb and MacTavish (2002), Grevsen and Sorensen (2004) and Miedema (1994). 
Regarding the effect of genotype, the separation among markers (Figure 5) shows that 'Vatikiotiko' is the onion genotype with the most marked differences, especially those related to function 1, among which dry matter, protein and energy (higher in 'Vatikiotiko') had the highest contribution. Function 2, which was particularly correlated to a* (lower in 'Creamgold') and Chroma values (higher in 'Creamgold') measured in the onion flesh, glucose and fructose (both higher in 'Creamgold'), was effective in individualizing 'Creamgold' from the remaining genotypes. As it can also be deduced from Figure 5, 'Sivan F1' and 'Red Cross F1' were the onion genotypes with highest similarity, especially concerning their profiles in the variables with highest correlations with function 1 and 2 . In fact, these genotypes were only clustered separately through function 3 , which resulted to be particularly correlated to juice electrical conductivity, organic acids (lower in 'Sivan F1') and phenols (higher in 'Sivan F1'). The other variables selected as having discriminant ability were hue angle values (measured in the flesh), bulb firmness, sucrose, the unidentified sugar, oxalic, malic and fumaric acids, $\alpha$ tocopherol, C18:0, C18:3, SFA, PUFA, Ca, Mg, Na, Zn, DPPH scavenging activity, reducing power, $\beta$-carotene bleaching inhibition and flavonoids. The obtained classification performance was $100 \%$ accurate, either for original grouped cases, as well as for the cross-validated grouped cases. These results confirm the fact that storage behavior of onion bulbs is highly depended on genotype; therefore the segregation of cultivars according to their storage potential based on photoperiodic requirements for bulbing (short, medium, intermediate and long day cultivars), tunic color (red and white colored tunic) and dry matter content is essential for better storage management (Gubb and MacTavish, 2002; Swee-Suak et al., 2002; Grevsen and Sorensen, 2004).

\section{Conclusions}


Among the three assayed factors, temperature, storage time and genotype, the one with the least influence in the chemical, physical and bioactive profiles of the assayed onion genotypes was temperature, especially when short-term storage is applied (up to 4 months). The fact that in our study storage period extended up to the time point where bulbs were unmarketable due to early sprouting and low visual appearance, indicates that storage for shortterms could be applied at either 5 or $25^{\circ} \mathrm{C}$, without significant differences in marketability. These results might have important practical applications since storage at cold rooms represents a high cost in food industry market, especially for bulk products such as onion bulbs. On the other hand, the storage time has markedly influenced several bulb quality parameters, and it might be optimized to allow onions exhibiting a particular set of characteristics. Furthermore, the four assayed onion genotypes presented important differences in the characterized parameters, which might represent the possibility of adapting a determined genotype to a specific use, thereby granting an important added-value to a specific genotype. Therefore, the local landrace of onion "Vatikiotiko" can be considered as a "storage" onion by retaining its marketability and nutritional quality for up to 7 months and significantly longer than the other genotypes assessed in the present study. This important feature has to be capitalized by increasing total production of this landrace in order to cover market needs for fresh produce in late spring and early summer, as well as the needs for stored onion in late autumn and early winter when there is lack of fresh produce. Furthermore it would be interesting to practice late sowing (within February) and harvest onion bulbs within mid-summer in order to cover the market needs throughout winter and early spring of the next season where quality of other stored onions is marginally acceptable.

\section{References}


Abayomi, L. A., Terry, L. A. (2008). Implications of spatial and temporal changes in concentration of pyruvate and glucose in onion (Allium cepa L.) bulbs during controlled atmosphere storage. Journal of the Science of Food and Agriculture, 89, 683-687.

Adamicki, F. 2005). Effects of pre-harvest treatments and storage conditions on quality and shelf-life of onions. Acta Horticulturae, 688, 229-238.

AOAC. (1995). Official Methods of Analysis. Association of Official Analytical Chemists: Arlington VA, USA, Vol. 16.

Baloch, J.-U.-D., Baloch, S., Munir, M., Alizai, A. A. (2012). A study on root growth of onion (Allium cepa L.) under storage conditions. Pakistan Journal of Life and Social Sciences, 10(2), 156-160.

Barros, L., Oliveira, S., Carvalho, A. M., Ferreira I. C. F. R. (2010). In vitro antioxidant properties and characterization in nutrients and phytochemicals of six medicinal plants from the Portuguese folk medicine. Industrial Crops and Products, 32, 572-579.

Benkeblia, N., Varoquaux, P., Shiomi, N., Sakai, H. (2002). Storage technology of onion bulbs cv. Rouge Ampusta: effects of irradiation, maleic hydrazide and carbamate isopropyl, Nphenyl (CIP) on respiration rate and carbohydrates. International Journal of Food Science and Nutrition, 37, 169-175.

Benkeblia, N., Varoquaux, P. (2003). Effetcs of nitrous oxide (N2O) on respiration rate, soluble sugars and quality attributes of onion bulbs Allium cepa L. Rouge Amposta during storage. Postharvest Biology and Technology, 30, 161-168.

Benkeblia, N., Onodera, S., Yoshihira, T., Kosaka, S., Shiomi, N. (2004). Effect of temperature on soluble invertase activity, and glucose, fructose and sucrose status of onion bulbs (Allium cepa) in store. International Journal of Food Sciences and Nutrition, 55(4), 325-331.

Benkeblia, N., Onodera, S., Shiomi, N. (2005a). Variation in 1-fructo-exohydrolase (1-FEH) and i-kestose-hydrolysing (1-KH) activities and fructo-oligosaccharide (FOS) status in onion 
bulbs. Influence of temperature and storage time. Journal of the Science of Food and Agriculture, 85, 227-334.

Benkeblia, N., Ueno, K., Onodera, S., Shiomi, N. (2005b). Variation of fructooligosaccharides and their metabolizing enzymes in onion bulb (Allium cepa L. cv. Tenshin) during long-term storage. Journal of Food Science, 70(3), 208-214.

Brewster, J. L. (2008). Onions and other vegetable alliums. 2nd ed. Wallingford, CAB International, p.433.

Chen, X. D., Mujumbar, A. (2008). Drying technologies in food processing. Blackwell Publishing Ltd., United Kingdom, pp. 26-29.

Chope, G. A., Terry, L. A., White, P. J. (2006). Effect of controlled atmosphere storage on abscisic acid concentration and other biochemical attributes of onion bulbs. Postharvest Biology and Technology, 39, 233-242.

Chope, G. A., Terry, L. A., White, P. J. (2007). The effect of the transition between controlled atmosphere and regular atmosphere storage on bulbs of onion cultivars SS1, Carlow and Renate. Postharvest Biology and Technology, 44, 228-239.

Chope, G. A., Cools, K., Hammond, J. P., Thompson, A. J., Terry, L. A. (2012). Physiological, biochemical and transcriptional analysis of onion bulbs during storage. Annals of Botany, $109,819-831$.

Coolong, T. W., Randle, W. M., Wicker, L. (2008). Structural and chemical differences in the cell wall regions in relation to scale firmness of three onion (Allium cepa L.) selections at harvest and during storage. Journal of the Science of Food and Agriculture, 88, 1277-1286.

Coolong, T. W., Randle, W. M. (2008). The effects of calcium chloride and ammonium sulfate on onion bulb quality at harvest and during storage. HortScience, 43(2), 465-471. 
Cools, K., Chope, G. A., Terry, L. A. (2010). Fate of flavonoids in the outer skins of onion (Allium cepa L.) throughout curing. Journal of Agricultural and Food Chemistry, 58, 1170911715.

Davis, F., Terry L. A., Chope, G. A., Faul, C. F. J. (2007). Effect of extraction procedure on measured sugar concentrations in onion (Allium cepa L.) bulbs. Journal of Agricultural and Food Chemistry, 55, 4299-4306.

Downes, K., Chope, G. A., Terry, L. A. (2009). Effect of curing at different temperatures on biochemical composition of onion (Allium cepa L.) skin from three freshly cured and cold stored UK-grown onion cultivars. Postharvest Biology and Technology, 54, 80-86.

Eshel, D., Tepper-Bamnolker, P., Vinokur, Y., Saad, I., Zutahy, Y. (2014). Fast-curing: a method to improve postharvest quality of onions in hot climate harvest. Postharvest Biology and Technology, 88, 34-39.

FAO. (2011). Production and trade statistics. FAO, Rome, Italy

Forney, C. F., Jordan, M. A., Campbell-Palmer, L., Fillmore, S., McRae, K., Best, K. (2010). Sulfur fertilization affects onion quality and flavor chemistry during storage. Acta Horticulturae, 877, 163-168.

Goyeneche, R., Agüero, M. V., Roura, S., Di Scala, K. (2014). Application of citric acid and mild heat shock to minimally processed sliced radish: Colour evauation. Postharvest Biology and Technology, 93, 106-113.

Grevsen, K., Sorensen, J. N. (2004). Sprouting and yield in bulb onions (Allium cepa L.) as influenced by cultivar, plant establishment methods, maturity at harvest and storage conditions. Journal of Horticultural Science and Biotechnology, 79(6), 877-884.

Grzelak, K., Milala, J., Król, B., Adamicki, F., Badelek, E. (2009). Content of quercetin glycosides and fructooligosaccharides in onion stored in a cold room. European Food Research and Technology, 228, 1001-1007. 
Gubb, I. R., MacTavish, H. S. (2002). Onion pre- and post-harvest considerations. Pp. 233-266. In: Rabinowitch, H. D. and Currah, L. (eds.). Allium crop sciences: recent advances. CAB International, Wallingford, UK.

Guimarães, R., Barros, L., Dueñas, M., Calhelha, R. C., Carvalho, A. M., Santos-Buelga, S., Queiroz, M. J. R. P., Ferreira, I. C. F. R. (2013). Nutrients, phytochemicals and bioactivity of wild Roman chamomile: A comparison between the herb and its preparations. Food Chemistry, 136, 718-725.

Hansen, S. L. (1999). Content and composition of dry matter in onion (Allium cepa) as influenced by their developmental stage at time of harvest, and long-term storage. Acta Agriculturae Scandinavica, Section B-Soil and Plant Science, 49, 103-109.

Hansen, S. L. (2001). Content of free amino acids in onion (Allium cepa L.) as influenced by the stage of development at harvest and long-term storage. Acta Agriculturae Scandinavica, Section B-Soil and Plant Science, 51(2), 77-83.

Hole, C. C., Drew, R. L. K., Gray, D. (2002). Skin characteristics and quality of onion cultivars given different nitrogen and irrigation treatments. Journal of Horticultural Science and Biotechnology, 77, 191-199.

Ilić, Z., Milenković, L., Djurovka, M., Traiković, R. (2009). The effect of long-term storage on quality attributes and storage potential of different onion cultivars. Proceedings of the IVth Balkan Symposium on Vegetables and Potatoes. Acta Horticulturae, 830, 635-642.

Jaime, L., Martín-Cabrejas, M. A., Mollá, E., López-Andréu, F. J., Esteban, R. M. (2001). Effect of storage on fructan and fructooligosaccharide of onion (Allium cepa L.). Journal of Agricultural and Food Chemistry, 49(2), 982-988.

Kumar, S., Imtiyaz, M., Kumar, A. (2007). Effect of differential soil moisture and nutrient regimes on postharvest attributes of onion (Allium cepa L.). Scientia Horticulturae, 112, 121-129. 
Lee, J., Mitchell, A. E. (2011). Quercetin and isorhamnetin glycosides in onion (Allium cepa L.): varietal comparison, physical distribution, coproduct evaluation, and long-term storage stability. Journal of Agricultural and Food Chemistry, 59(3), 857-863.

McGuire, R. G. (1992). Reporting of objective color measurements. HortScience, 27, 12541255.

Melo, C. O., Moretti, C. L., Machado, C. M. M., Mattos, L. M., Muniz, L. B. (2012). Chemical and physical alterations in storaged onion genotypes under refrigeration. Ciencia Rural, 42(11), 2078-2084.

Miedema, P. (1994). Bulb dormancy in onion. The effects of temperatures and cultivar on different onion cultivars. Journal of Horticultural Science, 69, 29-39.

Mogren, L. M., Olsson, M. E., Gertsson, U. E. (2007). Quercetin content in stored onions (Allium cepa L.): effects of storage conditions, cultivar, lifting time and nitrogen fertiliser level. Journal of the Science of Food and Agriculture, 87, 1595-1602.

Olsson, M. E., Gustavsson, K.-E., Vagen, I. M. (2010). Quercetin and isorhamnetin in sweet and red cultivars of onion (allium cepa L.) at harvest, after field curing, heat treatment, and storage. Journal of Agricultural and Food Chemistry, 58, 2323-2330.

Pereira, C., Barros, L., Carvalho, A. M., Ferreira, I. C. F. R. (2013). Use of UFLC-PDA for the analysis of organic acids in thirty-five species of food and medicinal plants. Food Analytical Methods, 6, 1337-1344.

Petropoulos, S. A., Fernandes, Â., Barros, L., Ferreira, I. C. F. R., Ntatsi, G. (2015). Morphological, nutritional and chemical description of "Vatikiotiko", an onion local landrace from Greece. Food Chemistry, 182, 156-163.

Rattin, J. E., Assuero, S. G., Sasso, G. A., Tognetti, J. A. (2011). Accelerated storage losses in onion subjected to water deficit during bulb filling. Scientia Horticulturae, 130, 25-31. 
Rivera, M., Fernandey, P., Andres, A. (2005). Evaluation of local onion lines from northwest Spain. Spanish Journal of Agricultural Research, 3(1), 90-97.

Rodrigues, A. S., Almeida, D. P. F., García-Falcón, M. S., Simal-Gándara, J., Pérez-Gregorio, M. R. (2010a). Postharvest storage systems affect phytochemical content and quality of traditional Portuguese onion cultivars. Acta Horticulturae, 934, 1327-1334.

Rodrigues, A. S., Pérez-Gregorio, M. R., García-Falcón, M. S., Simal-Gándara, J., Almeida, D. P. F. (2010b). Effect of post-harvest practices on flavonoid content of red and white onion cultivars. Food Control, 21, 878-884.

Roriz, C. L., Barros, L., Carvalho, A. M., Santos-Buelga, C., \& Ferreira, I. C. F. R. (2014). Pterospartum tridentatum, Gomphrena globosa and Cymbopogon citratus: A phytochemical study focused on antioxidant compounds. Food Research International, 62, 684-693.

Sharma, P. K. , Kumar, S., Yadav, G. L., Verma, R., Gupta, A. (2007). Effect of last irrigation and field curing on yield and post-harvest losses of rabi onion (Allium cepa). Annals of Biology, 23(2), 145-148.

Sharma, K., Asnin, L., Ko, E. Y., Lee, E. T., Park, S. W. (2014). Phytochemical composition of onion during long-term storage. Acta Agriculturae Scandinavica, Section B-Soil and Plant Science, 65, 150-160.

Sharma, K., Ko, E. Y., Assefa, A. D., Nile, S. H., Park, S. W. (2015). A comparative study of anaerobic and aerobic decomposition of quercetin glucosides and sugars in onion at an ambient temperature. Frontiers in Life Sciences, 8(2), 117-123.

Swee-Suak, K., Chang, W. N., Wang, J. F., Cherng, S. J., Shanmugasundaram, S. (2002). Storage variability among short-day onion cultivars under high temperature and high relative humidity, and its relationship with disease incidence and bulb characteristics. Journal of the American Society of Horticultural Science, 127, 848-854. 
Thangasamy, A., Sankar, V., Lawande, K. E. (2013). Effect of sulphur nutrition on pungency and storage life of short day onion (Allium cepa). Indian Journal of Agricultural Sciences, 83(10), 1086-1089.

Yoo, K. S., Lee, E. J., Patil, B. S. (2012). Changes in flavor precursors, pungency, and sugar content in short-day onion bulbs during 5-month storage at various temperatures or in controlled atmospheres. Journal of Food Science, 77, 216-221.

Yoo, K. S., Lee, E. J., Patil, B. S. (2013). Changes in the quercetin glucoside concentrations of onion bulbs by scales, during storage, and in sprouting leaves exposed to UV. Postharvest Biology and Biotechnology, 83, 65-71.

Zielinski, A. A. F., Haminiuk, C. W. I., Alberti, A., Nogueira, A., Demiate, I. M., Granato, D. (2014). A comparative study of the phenolic compounds and the in vitro antioxidant activity of different Brazilian teas using multivariate statistical techniques. Food Research International, 60, 246-254. 
Table 1. Quality features of the studied onion bulbs (mean \pm SD) in relation to storage time (days) and storage temperature $\left(5\right.$ and $\left.25{ }^{\circ} \mathrm{C}\right)$.

\begin{tabular}{|c|c|c|c|c|c|c|c|c|}
\hline $\mathrm{G}^{*}$ & $\begin{array}{l}\mathrm{T}^{*} \\
\left({ }^{\circ} \mathrm{C}\right)\end{array}$ & $\begin{array}{l}\text { ST* }^{*} \\
\text { (Days) }\end{array}$ & $\begin{array}{l}\text { Dry Matter } \\
(\%)\end{array}$ & Firmness (Kg) & $\begin{array}{l}\text { TSS } \\
\left({ }^{\circ} \text { Brix }\right)\end{array}$ & $\begin{array}{l}\text { TA } \\
(\%)\end{array}$ & $\mathrm{pH}$ & $\begin{array}{l}\mathrm{EC} \\
(\mathrm{dS} / \mathrm{m})\end{array}$ \\
\hline \multirow{6}{*}{$\mathrm{RC}$} & \multirow{3}{*}{5} & 0 & $11.1 \pm 0.5$ & $7 \pm 2$ & $10 \pm 1$ & $0.04 \pm 0.01$ & $5.5 \pm 0.1$ & $1.2 \pm 0.1$ \\
\hline & & 126 & $7.7 \pm 0.4$ & $6 \pm 1$ & $8 \pm 1$ & $0.04 \pm 0.01$ & $5.7 \pm 0.1$ & $1.2 \pm 0.2$ \\
\hline & & 147 & $10.4 \pm 0.3$ & $5 \pm 1$ & $9 \pm 1$ & $0.04 \pm 0.01$ & $5.7 \pm 0.1$ & $1.1 \pm 0.1$ \\
\hline & \multirow[t]{3}{*}{25} & 0 & $11.1 \pm 0.5$ & $7 \pm 2$ & $10 \pm 1$ & $0.04 \pm 0.01$ & $5.5 \pm 0.1$ & $1.2 \pm 0.1$ \\
\hline & & 126 & $8.2 \pm 0.3$ & $5 \pm 1$ & $9 \pm 1$ & $0.05 \pm 0.01$ & $5.4 \pm 01$ & $1.1 \pm 0.1$ \\
\hline & & $-* *$ & - & - & - & - & - & - \\
\hline \multirow{6}{*}{ S } & \multirow{3}{*}{5} & 0 & $11 \pm 2$ & $10 \pm 2$ & $10 \pm 1$ & $0.03 \pm 0.01$ & $5.5 \pm 0.1$ & $0.9 \pm 0.2$ \\
\hline & & 126 & $9 \pm 2$ & $8 \pm 2$ & $10 \pm 1$ & $0.03 \pm 0.01$ & $5.5 \pm 0.1$ & $0.9 \pm 0.1$ \\
\hline & & 182 & $10 \pm 1$ & $6 \pm 2$ & $9 \pm 1$ & $0.02 \pm 0.01$ & $5.6 \pm 0.1$ & $0.9 \pm 0.2$ \\
\hline & \multirow[t]{3}{*}{25} & 0 & $11 \pm 2$ & $10 \pm 2$ & $10 \pm 1$ & $0.03 \pm 0.01$ & $5.5 \pm 0.1$ & $0.9 \pm 0.2$ \\
\hline & & 126 & $9 \pm 2$ & $6 \pm 2$ & $10.1 \pm 0.5$ & $0.04 \pm 0.02$ & $5.3 \pm 0.2$ & $1.0 \pm 0.2$ \\
\hline & & 153 & $10 \pm 2$ & $5 \pm 1$ & $10 \pm 1$ & $0.5 \pm 0.02$ & $5.5 \pm 0.1$ & $1.0 \pm 0.2$ \\
\hline \multirow{6}{*}{$\mathrm{V}$} & \multirow{3}{*}{5} & 0 & $16 \pm 1$ & $14 \pm 3$ & $14.0 \pm 0.2$ & $0.04 \pm 0.01$ & $5.5 \pm 0.2$ & $1.5 \pm 0.1$ \\
\hline & & 126 & $12 \pm 1$ & $9 \pm 2$ & $14.4 \pm 0.5$ & $0.06 \pm 0.03$ & $5.6 \pm 0.2$ & $1.6 \pm 0.3$ \\
\hline & & 210 & $16 \pm 1$ & $8 \pm 2$ & $14 \pm 1$ & $0.04 \pm 0.02$ & $5.2 \pm 0.1$ & $1.6 \pm 0.2$ \\
\hline & \multirow[t]{3}{*}{25} & 0 & $16 \pm 1$ & $14 \pm 3$ & $14.0 \pm 0.2$ & $0.04 \pm 0.01$ & $5.5 \pm 0.2$ & $1.5 \pm 0.1$ \\
\hline & & 126 & $15 \pm 1$ & $9 \pm 2$ & $13 \pm 1$ & $0.06 \pm 0.04$ & $5.3 \pm 0.2$ & $1.5 \pm 0.1$ \\
\hline & & 210 & $6 \pm 1$ & $8 \pm 1$ & $13.4 \pm 0.4$ & $0.03 \pm 0.02$ & $5.3 \pm 0.3$ & $1.2 \pm 0.2$ \\
\hline \multirow{4}{*}{$\mathrm{C}$} & \multirow{3}{*}{5} & 0 & $11.1 \pm 0.3$ & $9 \pm 3$ & $11 \pm 1$ & $0.03 \pm 0.01$ & $5.8 \pm 0.1$ & $1.1 \pm 0.2$ \\
\hline & & 126 & $11.8 \pm 0.4$ & $9 \pm 2$ & $10 \pm 1$ & $0.04 \pm 0.03$ & $5.6 \pm 0.3$ & $1.0 \pm 0.1$ \\
\hline & & 210 & $11.4 \pm 0.5$ & $9 \pm 2$ & $9.4 \pm 0.5$ & $0.02 \pm 0.02$ & $5.4 \pm 0.1$ & $1.0 \pm 0.2$ \\
\hline & 25 & 0 & $11.1 \pm 0.3$ & $9 \pm 3$ & $11 \pm 1$ & $0.03 \pm 0.01$ & $5.8 \pm 0.1$ & $1.1 \pm 0.2$ \\
\hline
\end{tabular}




\begin{tabular}{|l|l|l|l|l|l|l|l|}
\hline level & T x ST & 0.628 & $<0.001$ & 0.159 & $<0.001$ & $<0.001$ & $<0.001$ \\
\cline { 2 - 8 } & T x G & 0.001 & 0.435 & 0.005 & $<0.001$ & 0.009 & $<0.001$ \\
\cline { 2 - 7 } & ST x G & $<0.001$ & $<0.001$ & $<0.001$ & $<0.001$ & $<0.001$ & $<0.001$ \\
\cline { 2 - 7 } & $\begin{array}{l}\text { T X ST x } \\
\text { G }\end{array}$ & 0.005 & $<0.001$ & 0.114 & 0.003 & 0.022 & $<0.001$ \\
& & &
\end{tabular}

*TA: Titratable acidity is expressed in grams of anhydrous citric acid per $100 \mathrm{~g}$ of bulb fresh weight; $\mathrm{pH}$ and Electric Conductivity (EC) of juice.

G: Genotype (RC: Red Cross F1, S: Sivan F1, V: Vatikiotiko, C: Creamgold), T: Temperature, ST: Storage time; **-: Not measured due to early sprouting. 
Table 2. Nutritional value of the studied onion samples (mean \pm SD) in relation to storage time (days) and storage temperature $\left(5\right.$ and $\left.25^{\circ} \mathrm{C}\right)$.

\begin{tabular}{|c|c|c|c|c|c|c|c|}
\hline $\mathrm{G}^{*}$ & $\mathrm{~T}^{*}\left({ }^{\circ} \mathrm{C}\right)$ & ST* (Days) & $\begin{array}{l}\text { Ash } \\
(\mathrm{g} / 100 \mathrm{~g} \mathrm{fw})\end{array}$ & $\begin{array}{l}\text { Proteins } \\
(\mathrm{g} / 100 \mathrm{~g} \mathrm{fw})\end{array}$ & $\begin{array}{l}\text { Fat } \\
(\mathrm{g} / 100 \mathrm{~g} \mathrm{fw})\end{array}$ & $\begin{array}{l}\text { Carbohydrates } \\
\text { (g/100 g fw) }\end{array}$ & $\begin{array}{l}\text { Energy } \\
\text { (kcal/100 g fw) }\end{array}$ \\
\hline \multirow{6}{*}{$\mathrm{RC}$} & \multirow{3}{*}{5} & 0 & $0.40 \pm 0.01$ & $0.62 \pm 0.03$ & $0.07 \pm 0.01$ & $10.01 \pm 0.03$ & $43.13 \pm 0.01$ \\
\hline & & 126 & $0.26 \pm 0.01$ & $0.09 \pm 0.01$ & $0.07 \pm 0.01$ & $7.27 \pm 0.01$ & $30.07 \pm 0.03$ \\
\hline & & 147 & $0.42 \pm 0.01$ & $0.39 \pm 0.01$ & $0.15 \pm 0.01$ & $9.43 \pm 0.01$ & $40.63 \pm 0.02$ \\
\hline & \multirow[t]{3}{*}{25} & 0 & $0.40 \pm 0.01$ & $0.62 \pm 0.03$ & $0.07 \pm 0.01$ & $10.01 \pm 0.03$ & $43.13 \pm 0.01$ \\
\hline & & 126 & $0.27 \pm 0.01$ & $0.11 \pm 0.01$ & $0.07 \pm 0.01$ & $7.78 \pm 0.01$ & $32.15 \pm 0.04$ \\
\hline & & $-* *$ & - & - & - & - & - \\
\hline \multirow{6}{*}{ S } & \multirow{3}{*}{5} & 0 & $0.36 \pm 0.01$ & $0.61 \pm 0.01$ & $0.07 \pm 0.01$ & $9.91 \pm 0.01$ & $42.67 \pm 0.03$ \\
\hline & & 126 & $0.30 \pm 0.01$ & $0.20 \pm 0.03$ & $0.12 \pm 0.01$ & $8.48 \pm 0.04$ & $35.79 \pm 0.01$ \\
\hline & & 182 & $0.39 \pm 0.01$ & $0.30 \pm 0.03$ & $0.11 \pm 0.01$ & $8.68 \pm 0.03$ & $36.93 \pm 0.05$ \\
\hline & \multirow[t]{3}{*}{25} & 0 & $0.36 \pm 0.01$ & $0.61 \pm 0.01$ & $0.07 \pm 0.01$ & $9.91 \pm 0.01$ & $42.67 \pm 0.01$ \\
\hline & & 126 & $0.35 \pm 0.01$ & $0.26 \pm 0.01$ & $0.11 \pm 0.01$ & $8.72 \pm 0.01$ & $36.94 \pm 0.03$ \\
\hline & & 153 & $0.42 \pm 0.01$ & $0.34 \pm 0.01$ & $0.16 \pm 0.01$ & $9.17 \pm 0.01$ & $39.48 \pm 0.02$ \\
\hline \multirow{6}{*}{ V } & \multirow{3}{*}{5} & 0 & $0.58 \pm 0.01$ & $0.94 \pm 0.01$ & $0.10 \pm 0.01$ & $14.40 \pm 0.01$ & $62.26 \pm 0.01$ \\
\hline & & 126 & $0.72 \pm 0.02$ & $1.08 \pm 0.02$ & $0.28 \pm 0.01$ & $12.39 \pm 0.02$ & $56.39 \pm 0.03$ \\
\hline & & 210 & $0.96 \pm 0.02$ & $1.58 \pm 0.03$ & $0.30 \pm 0.01$ & $12.89 \pm 0.04$ & $60.59 \pm 0.03$ \\
\hline & \multirow[t]{3}{*}{25} & 0 & $0.58 \pm 0.01$ & $0.94 \pm 0.01$ & $0.10 \pm 0.01$ & $14.40 \pm 0.01$ & $62.26 \pm 0.01$ \\
\hline & & 126 & $0.75 \pm 0.05$ & $1.15 \pm 0.01$ & $0.27 \pm 0.01$ & $12.82 \pm 0.04$ & $58.3 \pm 0.2$ \\
\hline & & 210 & $1.06 \pm 0.01$ & $1.30 \pm 0.03$ & $0.35 \pm 0.01$ & $12.99 \pm 0.03$ & $60.30 \pm 0.04$ \\
\hline \multirow{6}{*}{$\mathrm{C}$} & \multirow{3}{*}{5} & 0 & $0.32 \pm 0.01$ & $0.58 \pm 0.01$ & $0.06 \pm 0.01$ & $10.15 \pm 0.01$ & $43.48 \pm 0.01$ \\
\hline & & 126 & $0.57 \pm 0.01$ & $0.72 \pm 0.03$ & $0.20 \pm 0.01$ & $10.28 \pm 0.03$ & $45.80 \pm 0.05$ \\
\hline & & 210 & $0.57 \pm 0.01$ & $0.50 \pm 0.01$ & $0.19 \pm 0.01$ & $10.17 \pm 0.02$ & $44.4 \pm 0.1$ \\
\hline & \multirow[t]{3}{*}{25} & 0 & $0.32 \pm 0.01$ & $0.58 \pm 0.01$ & $0.06 \pm 0.01$ & $10.15 \pm 0.01$ & $43.48 \pm 0.01$ \\
\hline & & 126 & $0.44 \pm 0.01$ & $0.40 \pm 0.01$ & $0.15 \pm 0.01$ & $9.41 \pm 0.01$ & $40.60 \pm 0.02$ \\
\hline & & 139 & $0.54 \pm 0.01$ & $0.59 \pm 0.02$ & $0.19 \pm 0.01$ & $9.84 \pm 0.03$ & $43.44 \pm 0.05$ \\
\hline \multirow{3}{*}{\multicolumn{2}{|c|}{$\begin{array}{l}\mathrm{p} \text { values at } 95 \% \\
\text { confidence level }\end{array}$}} & $\mathrm{T}$ & 0.641 & 0.170 & 0.027 & 0.107 & 0.144 \\
\hline & & ST & $<0.001$ & $<0.001$ & $<0.001$ & $<0.001$ & $<0.001$ \\
\hline & & $\mathrm{G}$ & $<0.001$ & $<0.001$ & $<0.001$ & $<0.001$ & $<0.001$ \\
\hline
\end{tabular}




\begin{tabular}{|l|l|l|l|l|l|l|}
\hline & Tx ST & 0.041 & 0.002 & $<0.001$ & 0.401 & 0.149 \\
\cline { 2 - 6 } & Tx G & $<0.001$ & $<0.001$ & $<0.001$ & $<0.001$ & $<0.001$ \\
\cline { 2 - 6 } & ST X G & $<0.001$ & $<0.001$ & $<0.001$ & $<0.001$ & $<0.001$ \\
\cline { 2 - 5 } & 0.001 & $<0.001$ & $<0.001$ & $<0.001$ & $<0.001$ \\
\hline
\end{tabular}

${ }^{*}$ G: Genotype (RC: Red Cross F1, S: Sivan F1, V: Vatikiotiko, C: Creamgold), T: Temperature, ST: Storage time; **-: Not measured due to early sprouting. 
Table 3. Organic acids composition of the studied onion samples $(\mathrm{mg} / 100 \mathrm{~g}$ fw; mean $\pm \mathrm{SD})$ in relation to storage time (days) and storage temperature $\left(5\right.$ and $\left.25^{\circ} \mathrm{C}\right)$.

\begin{tabular}{|c|c|c|c|c|c|c|c|c|}
\hline $\mathrm{G}^{*}$ & $\mathrm{~T}^{*}\left({ }^{\circ} \mathrm{C}\right)$ & $\begin{array}{l}\text { ST* }^{*} \\
\text { (Days) }\end{array}$ & Oxalic Acid & Malic acid & Ascorbic acid & Citric acid & Fumaric acid & Total \\
\hline \multirow[t]{6}{*}{$\mathrm{RC}$} & \multirow{3}{*}{5} & 0 & $20.3 \pm 0.2$ & $171 \pm 6$ & $1.9 \pm 0.2$ & $210 \pm 8$ & $0.10 \pm 0.01$ & $403 \pm 14$ \\
\hline & & 126 & $44.5 \pm 0.2$ & $227 \pm 7$ & $2.3 \pm 0.2$ & $63 \pm 4$ & $0.03 \pm 0.01$ & $337 \pm 11$ \\
\hline & & 147 & $49.4 \pm 0.1$ & $319 \pm 9$ & $4.6 \pm 0.3$ & $76 \pm 5$ & $0.10 \pm 0.01$ & $450 \pm 15$ \\
\hline & \multirow[t]{3}{*}{25} & 0 & $20.3 \pm 0.2$ & $171 \pm 6$ & $1.9 \pm 0.2$ & $210 \pm 8$ & $0.10 \pm 0.01$ & $403 \pm 14$ \\
\hline & & 126 & $45.5 \pm 0.4$ & $242 \pm 7$ & $3.4 \pm 0.3$ & $133 \pm 6$ & $0.06 \pm 0.01$ & $424 \pm 4$ \\
\hline & & $-* *$ & - & - & - & - & - & - \\
\hline \multirow[t]{6}{*}{$\mathrm{S}$} & \multirow{3}{*}{5} & 0 & $19.3 \pm 0.1$ & $120 \pm 3$ & $2.8 \pm 0.1$ & $131 \pm 4$ & $0.04 \pm 0.01$ & $273 \pm 7$ \\
\hline & & 126 & $38.8 \pm 0.2$ & $119 \pm 3$ & $4.4 \pm 0.3$ & $75 \pm 4$ & $0.04 \pm 0.01$ & $237 \pm 2$ \\
\hline & & 182 & $49.0 \pm 0.4$ & $185 \pm 3$ & $5.4 \pm 0.2$ & $41 \pm 2$ & $0.16 \pm 0.02$ & $280 \pm 2$ \\
\hline & \multirow[t]{3}{*}{25} & 0 & $19.3 \pm 0.1$ & $120 \pm 3$ & $2.8 \pm 0.1$ & $131 \pm 4$ & $0.04 \pm 0.01$ & $273 \pm 7$ \\
\hline & & 126 & $34.2 \pm 0.1$ & $56 \pm 3$ & $5.2 \pm 0.2$ & $232 \pm 8$ & nd & $328 \pm 11$ \\
\hline & & 153 & $36.6 \pm 0.5$ & $78 \pm 3$ & $5.4 \pm 0.2$ & $325 \pm 12$ & nd & $444 \pm 9$ \\
\hline \multirow[t]{6}{*}{ V } & \multirow{3}{*}{5} & 0 & $46.1 \pm 0.2$ & $237 \pm 6$ & $3.8 \pm 0.1$ & $227 \pm 8$ & $0.14 \pm 0.01$ & $514 \pm 5$ \\
\hline & & 126 & $54.1 \pm 0.5$ & $227 \pm 7$ & $4.7 \pm 0.3$ & $145 \pm 5$ & $0.09 \pm 0.01$ & $430 \pm 4$ \\
\hline & & 210 & $63.1 \pm 0.5$ & $249 \pm 7$ & $3.5 \pm 0.2$ & $75 \pm 2$ & $0.39 \pm 0.04$ & $31 \pm 8$ \\
\hline & \multirow[t]{3}{*}{25} & 0 & $46.1 \pm 0.2$ & $237 \pm 6$ & $3.8 \pm 0.1$ & $227 \pm 8$ & $0.14 \pm 0.01$ & $514 \pm 5$ \\
\hline & & 126 & $56.4 \pm 0.1$ & $216 \pm 5$ & $2.9 \pm 0.1$ & $333 \pm 12$ & nd & $609 \pm 8$ \\
\hline & & 210 & $73.2 \pm 0.5$ & $174 \pm 5$ & $1.5 \pm 0.1$ & $450 \pm 17$ & nd & $698 \pm 12$ \\
\hline \multirow[t]{5}{*}{$\mathrm{C}$} & \multirow{3}{*}{5} & 0 & $34.9 \pm 0.2$ & $146 \pm 3$ & $4.2 \pm 0.2$ & $123 \pm 4$ & nd & $308 \pm 7$ \\
\hline & & 126 & $56 \pm 1$ & $540 \pm 13$ & $4.2 \pm 0.3$ & nd & $0.7 \pm 0.1$ & $600 \pm 14$ \\
\hline & & 210 & $58.9 \pm 0.4$ & $246 \pm 6$ & $5.0 \pm 0.2$ & nd & $0.04 \pm 0.01$ & $310 \pm 6$ \\
\hline & \multirow[t]{2}{*}{25} & 0 & $34.9 \pm 0.2$ & $146 \pm 3$ & $4.2 \pm 0.2$ & $123 \pm 4$ & nd & $308 \pm 7$ \\
\hline & & 126 & $48 \pm 1$ & $159 \pm 4$ & $7.5 \pm 0.2$ & $117 \pm 1$ & $0.02 \pm 0.01$ & $331 \pm 5$ \\
\hline
\end{tabular}




\begin{tabular}{|l|l|l|l|l|l|l|l|}
\hline & 139 & $57 \pm 1$ & $285 \pm 7$ & $3.4 \pm 0.1$ & $161 \pm 7$ & $0.15 \pm 0.01$ & $507 \pm 3$ \\
\hline \multirow{3}{*}{$\begin{array}{l}\text { p values at 95\% } \\
\text { confidence level }\end{array}$} & T & $<0.001$ & $<0.001$ & 0.015 & $<0.001$ & $<0.001$ & $<0.001$ \\
\cline { 2 - 8 } & ST & $<0.001$ & $<0.001$ & $<0.001$ & $<0.001$ & $<0.001$ & $<0.001$ \\
\cline { 2 - 8 } & G & $<0.001$ & $<0.001$ & $<0.001$ & $<0.001$ & $<0.001$ & $<0.001$ \\
\cline { 2 - 8 } & T x ST & $<0.001$ & $<0.001$ & $<0.001$ & $<0.001$ & $<0.001$ & $<0.001$ \\
\cline { 2 - 8 } & T x G & $<0.001$ & $<0.001$ & $<0.001$ & $<0.001$ & $<0.001$ & $<0.001$ \\
\cline { 2 - 8 } & ST X G & $<0.001$ & $<0.001$ & $<0.001$ & $<0.001$ & $<0.001$ & $<0.001$ \\
\cline { 2 - 8 } & T X ST & $<0.001$ & $<0.001$ & $<0.001$ & $<0.001$ & $<0.001$ & $<0.001$ \\
\hline
\end{tabular}

*G: Genotype (RC: Red Cross F1, S: Sivan F1, V: Vatikiotiko, C: Creamgold), T: Temperature, ST: Storage time; **: Not measured due to early sprouting. 
Table 4. Sugars composition of the studied onion samples $(\mathrm{mg} / 100 \mathrm{~g}$ fw; mean $\pm \mathrm{SD})$ in relation to storage time (days) and storage temperature $\left(5\right.$ and $\left.25^{\circ} \mathrm{C}\right)$.

\begin{tabular}{|c|c|c|c|c|c|c|c|c|}
\hline $\mathrm{G}^{*}$ & $\mathrm{~T}^{*}\left({ }^{\circ} \mathrm{C}\right)$ & $\begin{array}{l}\text { ST* }^{*} \\
\text { (Days) }\end{array}$ & Fructose & Glucose & Sucrose & Trehalose & Unidentified & Total \\
\hline \multirow[t]{6}{*}{$\mathrm{RC}$} & \multirow{3}{*}{5} & 0 & $1.2 \pm 0.1$ & $1.5 \pm 0.1$ & $0.5 \pm 0.1$ & $0.03 \pm 0.01$ & $0.14 \pm 0.01$ & $3.4 \pm 0.2$ \\
\hline & & 126 & $2.2 \pm 0.1$ & $1.9 \pm 0.1$ & $0.5 \pm 0.1$ & $0.02 \pm 0.01$ & $0.02 \pm 0.01$ & $4.7 \pm 0.3$ \\
\hline & & 147 & $2.04 \pm 0.04$ & $2.11 \pm 0.02$ & $0.6 \pm 0.1$ & $0.03 \pm 0.01$ & $0.06 \pm 0.01$ & $4.8 \pm 0.1$ \\
\hline & \multirow[t]{3}{*}{25} & 0 & $1.2 \pm 0.1$ & $1.5 \pm 0.1$ & $0.5 \pm 0.1$ & $0.03 \pm 0.01$ & $0.14 \pm 0.01$ & $3.4 \pm 0.2$ \\
\hline & & 126 & $1.0 \pm 0.1$ & $1.3 \pm 0.1$ & $0.9 \pm 0.1$ & $0.01 \pm 0.01$ & $0.10 \pm 0.02$ & $3.2 \pm 0.2$ \\
\hline & & $-* *$ & & & & & & \\
\hline \multirow[t]{6}{*}{$\mathrm{S}$} & \multirow{3}{*}{5} & 0 & $1.9 \pm 0.1$ & $2.0 \pm 0.1$ & $0.6 \pm 0.1$ & $0.01 \pm 0.01$ & $0.12 \pm 0.02$ & $4.6 \pm 0.2$ \\
\hline & & 126 & $2.2 \pm 0.1$ & $2.0 \pm 0.1$ & $0.7 \pm 0.1$ & $0.02 \pm 0.01$ & $0.06 \pm 0.01$ & $5.0 \pm 0.2$ \\
\hline & & 182 & $1.7 \pm 0.1$ & $1.8 \pm 0.1$ & $0.6 \pm 0.1$ & $0.02 \pm 0.01$ & $0.09 \pm 0.01$ & $4.3 \pm 0.2$ \\
\hline & \multirow[t]{3}{*}{25} & 0 & $1.9 \pm 0.1$ & $2.0 \pm 0.1$ & $0.6 \pm 0.1$ & $0.01 \pm 0.01$ & $0.12 \pm 0.02$ & $4.6 \pm 0.2$ \\
\hline & & 126 & $1.7 \pm 0.1$ & $2.1 \pm 0.1$ & $1.47 \pm 0.05$ & $0.01 \pm 0.01$ & $0.08 \pm 0.01$ & $5.4 \pm 0.2$ \\
\hline & & 153 & $1.7 \pm 0.1$ & $2.31 \pm 0.04$ & $1.98 \pm 0.03$ & $0.01 \pm 0.01$ & $0.07 \pm 0.01$ & $6.1 \pm 0.1$ \\
\hline \multirow[t]{6}{*}{$\mathrm{V}$} & \multirow{3}{*}{5} & 0 & $0.4 \pm 0.1$ & $1.0 \pm 0.05$ & $0.72 \pm 0.04$ & $0.03 \pm 0.01$ & $0.39 \pm 0.02$ & $2.5 \pm 0.1$ \\
\hline & & 126 & $0.8 \pm 0.1$ & $0.8 \pm 0.1$ & $0.9 \pm 0.1$ & $0.02 \pm 0.01$ & $0.30 \pm 0.04$ & $2.8 \pm 0.2$ \\
\hline & & 210 & $1.2 \pm 0.1$ & $1.1 \pm 0.1$ & $1.1 \pm 0.1$ & $0.03 \pm 0.01$ & $0.31 \pm 0.03$ & $3.8 \pm 0.2$ \\
\hline & \multirow[t]{3}{*}{25} & 0 & $0.4 \pm 0.1$ & $0.98 \pm 0.05$ & $0.72 \pm 0.04$ & $0.03 \pm 0.01$ & $0.39 \pm 0.02$ & $2.5 \pm 0.1$ \\
\hline & & 126 & $0.7 \pm 0.1$ & $0.7 \pm 0.1$ & $1.3 \pm 0.1$ & $0.02 \pm 0.01$ & $0.39 \pm 0.03$ & $3.2 \pm 0.2$ \\
\hline & & 210 & $0.6 \pm 0.1$ & $0.6 \pm 0.1$ & $1.6 \pm 0.1$ & $0.03 \pm 0.01$ & $0.45 \pm 0.04$ & $3.4 \pm 0.2$ \\
\hline $\mathrm{C}$ & 5 & 0 & $0.4 \pm 0.1$ & $0.8 \pm 0.1$ & $0.8 \pm 0.1$ & $0.02 \pm 0.01$ & $0.29 \pm 0.05$ & $2.3 \pm 0.2$ \\
\hline
\end{tabular}




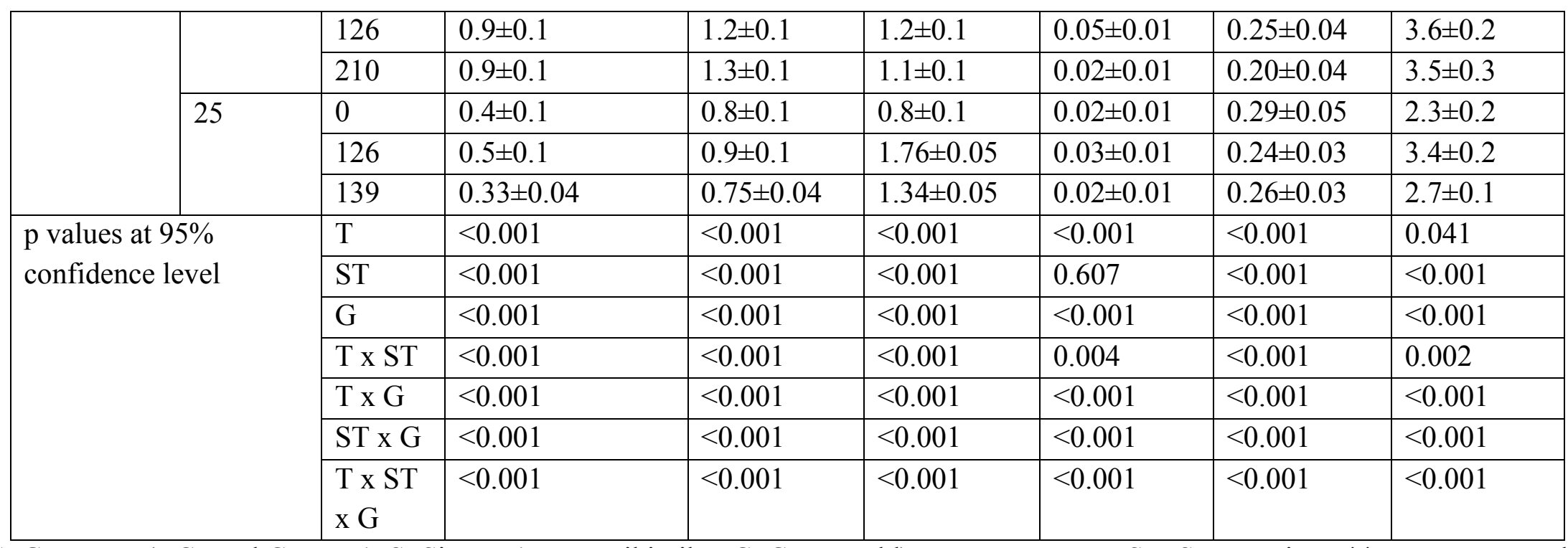

${ }^{*}$ G: Genotype (RC: Red Cross F1, S: Sivan F1, V: Vatikiotiko, C: Creamgold), T: Temperature, ST: Storage time; **-: Not measured due to early sprouting. 
Table 5. Minerals composition $(\mathrm{mg} / 100 \mathrm{~g}$ fw; mean $\pm \mathrm{SD}$ ) of the studied onion bulbs in relation to storage time (days) and storage temperature $(5$ and $\left.25^{\circ} \mathrm{C}\right)$.

\begin{tabular}{|c|c|c|c|c|c|c|c|c|c|}
\hline $\begin{array}{l}\text { Genotype } \\
\text { s* }^{*}\end{array}$ & $\begin{array}{l}\text { Temperature } \\
\left(0^{\circ} \mathrm{C}\right)\end{array}$ & $\begin{array}{l}\text { Storage } \\
\text { (Days) }\end{array}$ & $\mathrm{K}$ & $\mathrm{Ca}$ & $\mathrm{Mg}$ & $\mathrm{Na}$ & $\mathrm{Zn}$ & $\mathrm{Mn}$ & $\mathrm{Fe}$ \\
\hline \multirow{6}{*}{$\mathrm{RC}$} & \multirow{3}{*}{$(0,5)$} & 0 & $124 \pm 22$ & $116 \pm 27$ & $133 \pm 11$ & $10.4 \pm 0.2$ & $0.29 \pm 0.02$ & $0.4 \pm 0.1$ & $0.85 \pm 0.02$ \\
\hline & & 126 & $196 \pm 9$ & $27 \pm 1$ & $15 \pm 2$ & $7.9 \pm 0.3$ & $0.14 \pm 0.03$ & $0.19 \pm 0.01$ & $0.26 \pm 0.04$ \\
\hline & & 147 & $192 \pm 14$ & $54 \pm 4$ & $20 \pm 1$ & $4.6 \pm 0.4$ & $0.11 \pm 0.01$ & $0.28 \pm 0.01$ & $0.27 \pm 0.04$ \\
\hline & \multirow[t]{3}{*}{25} & 0 & $124 \pm 22$ & $116 \pm 27$ & $13 \pm 11$ & $10.4 \pm 0.2$ & $0.29 \pm 0.02$ & $0.4 \pm 0.1$ & $0.85 \pm 0.02$ \\
\hline & & 126 & $22 \pm 19$ & $56 \pm 5$ & $25 \pm 2$ & $6.0 \pm 0.4$ & $0.12 \pm 0.01$ & $0.17 \pm 0.01$ & $0.27 \pm 0.02$ \\
\hline & & $-*$ & - & - & - & - & - & - & - \\
\hline \multirow{6}{*}{ S } & \multirow{3}{*}{5} & 0 & $75 \pm 17$ & $103 \pm 6$ & $78 \pm 5$ & $12 \pm 2$ & $0.18 \pm 0.04$ & $0.19 \pm 0.02$ & $0.55 \pm 0.01$ \\
\hline & & 126 & $176 \pm 14$ & $32 \pm 3$ & $13 \pm 1$ & $9 \pm 1$ & $0.12 \pm 0.01$ & $0.17 \pm 0.02$ & $0.29 \pm 0.01$ \\
\hline & & 182 & $157 \pm 4$ & $39 \pm 5$ & $14 \pm 1$ & $12 \pm 2$ & $0.07 \pm 0.01$ & $0.17 \pm 0.01$ & $0.24 \pm 0.01$ \\
\hline & \multirow[t]{3}{*}{25} & 0 & $75 \pm 17$ & $103 \pm 6$ & $78 \pm 5$ & $12 \pm 2$ & $0.18 \pm 0.04$ & $0.19 \pm 0.02$ & $0.55 \pm 0.01$ \\
\hline & & 126 & $180 \pm 14$ & $43 \pm 3$ & $15 \pm 1$ & $9 \pm 1$ & $0.10 \pm 0.01$ & $0.17 \pm 0.02$ & $0.28 \pm 0.02$ \\
\hline & & 153 & $207 \pm 4$ & $38 \pm 2$ & $16 \pm 1$ & $9 \pm 1$ & $0.13 \pm 0.01$ & $0.18 \pm 0.02$ & $0.29 \pm 0.04$ \\
\hline \multirow{6}{*}{ V } & \multirow{3}{*}{5} & 0 & $61 \pm 6$ & $89 \pm 7$ & $94 \pm 8$ & $15 \pm 2$ & $0.12 \pm 0.01$ & $0.20 \pm 0.01$ & $0.55 \pm 0.05$ \\
\hline & & 126 & $313 \pm 6$ & $78 \pm 5$ & $30 \pm 3$ & $16 \pm 2$ & $0.35 \pm 0.04$ & $0.57 \pm 0.03$ & $0.58 \pm 0.04$ \\
\hline & & 210 & $273 \pm 16$ & $61 \pm 11$ & $25 \pm 2$ & $16 \pm 1$ & $0.29 \pm 0.01$ & $0.44 \pm 0.02$ & $0.40 \pm 0.04$ \\
\hline & \multirow[t]{3}{*}{25} & 0 & $61 \pm 6$ & $89 \pm 7$ & $94 \pm 8$ & $15 \pm 2$ & $0.12 \pm 0.01$ & $0.20 \pm 0.01$ & $0.55 \pm 0.05$ \\
\hline & & 126 & $209 \pm 21$ & $64 \pm 7$ & $24 \pm 2$ & $13 \pm 2$ & $0.24 \pm 0.01$ & $0.37 \pm 0.04$ & $0.45 \pm 0.03$ \\
\hline & & 210 & $264 \pm 25$ & $40 \pm 3$ & $28 \pm 2$ & $16 \pm 1$ & $0.30 \pm 0.04$ & $0.38 \pm 0.02$ & $0.47 \pm 0.04$ \\
\hline \multirow{5}{*}{$\mathrm{C}$} & \multirow{3}{*}{5} & 0 & $125 \pm 31$ & $67 \pm 8$ & $98 \pm 15$ & $9 \pm 1$ & $0.11 \pm 0.03$ & $0.17 \pm 0.02$ & $0.61 \pm 0.05$ \\
\hline & & 126 & $192 \pm 4$ & $31 \pm 3$ & $15 \pm 1$ & $11.6 \pm 0.2$ & $0.24 \pm 0.01$ & $0.31 \pm 0.03$ & $0.31 \pm 0.02$ \\
\hline & & 210 & $180 \pm 20$ & $32 \pm 3$ & $17 \pm 2$ & $9.9 \pm 0.4$ & $0.32 \pm 0.03$ & $0.30 \pm 0.02$ & $0.32 \pm 0.04$ \\
\hline & \multirow[t]{2}{*}{25} & 0 & $125 \pm 31$ & $67 \pm 8$ & $98 \pm 15$ & $9 \pm 1$ & $0.11 \pm 0.03$ & $0.17 \pm 0.02$ & $0.61 \pm 0.05$ \\
\hline & & 126 & $236 \pm 36$ & $31 \pm 2$ & $16 \pm 2$ & $6 \pm 1$ & $0.15 \pm 0.01$ & $0.27 \pm 0.03$ & $0.28 \pm 0.01$ \\
\hline
\end{tabular}




\begin{tabular}{|c|c|c|c|c|c|c|c|c|c|}
\hline & & 139 & $214 \pm 13$ & $20 \pm 3$ & $15 \pm 1$ & $9 \pm 1$ & $0.17 \pm 0.01$ & $0.29 \pm 0.01$ & $0.32 \pm 0.03$ \\
\hline \multirow{7}{*}{$\begin{array}{l}\mathrm{p} \text { values } \\
\text { at } 95 \% \\
\text { confidenc } \\
\text { e level }\end{array}$} & $\mathrm{T}$ & 0.016 & 0.773 & 0.238 & $<0.001$ & $<0.001$ & $<0.001$ & $<0.001$ & 0.656 \\
\hline & ST & $<0.001$ & $<0.001$ & $<0.001$ & $<0.001$ & $<0.001$ & $<0.001$ & $<0.001$ & $<0.001$ \\
\hline & G & $<0.001$ & $<0.001$ & $<0.001$ & $<0.001$ & $<0.001$ & $<0.001$ & $<0.001$ & $<0.001$ \\
\hline & T x ST & $<0.001$ & 0.001 & 0.616 & $<0.001$ & $<0.001$ & $<0.001$ & $<0.001$ & $<0.001$ \\
\hline & $\mathrm{T} \times \mathrm{G}$ & $<0.001$ & $<0.001$ & 0.101 & 0.002 & 0.002 & $<0.001$ & $<0.001$ & $<0.001$ \\
\hline & ST x G & $<0.001$ & $<0.001$ & $<0.001$ & $<0.001$ & $<0.001$ & $<0.001$ & $<0.001$ & $<0.001$ \\
\hline & T x ST x G & $<0.001$ & $<0.001$ & 0.068 & $<0.001$ & $<0.001$ & $<0.001$ & $<0.001$ & $<0.001$ \\
\hline
\end{tabular}

*G: Genotype (RC: Red Cross F1, S: Sivan F1, V: Vatikiotiko, C: Creamgold), T: Temperature, ST: Storage time; **-: Not measured due to early sprouting. 
Table 6. Main fatty acids (relative percentage; mean \pm SD) in the studied onion samples in relation to storage time (days) and storage temperature $\left(5\right.$ and $\left.25^{\circ} \mathrm{C}\right)$.

\begin{tabular}{|c|c|c|c|c|c|c|c|c|c|c|}
\hline $\mathrm{G}^{*}$ & $\mathrm{~T}^{*}\left({ }^{\circ} \mathrm{C}\right)$ & ST* (Days) $^{\prime}$ & C:16 & C:18 & C18:1n9 & C18:2n6 & C18:3n3 & $\begin{array}{l}\text { Total SFA ( } \% \\
\text { of total FA) }\end{array}$ & $\begin{array}{l}\text { Total MUFA (\% } \\
\text { of total FA) }\end{array}$ & $\begin{array}{l}\text { Total PUFA ( } \% \\
\text { of total FA) }\end{array}$ \\
\hline \multirow{4}{*}{$\mathrm{RC}$} & 5 & 126 & $23 \pm 1$ & $5 \pm 1$ & $10 \pm 1$ & $48 \pm 1$ & $5.4 \pm 0.4$ & $36 \pm 1$ & $11.6 \pm 0.2$ & $53 \pm 1$ \\
\hline & \multirow[t]{3}{*}{25} & 0 & $22 \pm 1$ & $8 \pm 1$ & $21 \pm 1$ & $40 \pm 1$ & $4.4 \pm 0.3$ & $36 \pm 1$ & $20.4 \pm 0.3$ & $43 \pm 1$ \\
\hline & & 126 & $2 \pm 1$ & $3.4 \pm 0.4$ & $18 \pm 1$ & $42 \pm 1$ & $5.2 \pm 0.2$ & $34.5 \pm 0.5$ & $18.7 \pm 0.4$ & $46.8 \pm 0.5$ \\
\hline & & $-* *$ & - & - & - & - & - & - & - & - \\
\hline \multirow{4}{*}{$\mathrm{S}$} & 5 & 182 & $20 \pm 1$ & $2.5 \pm 0.3$ & $10.7 \pm 0.3$ & $52 \pm 1$ & $4.6 \pm 0.4$ & $33.2 \pm 0.5$ & $11.2 \pm 0.1$ & $56 \pm 1$ \\
\hline & \multirow[t]{3}{*}{25} & 0 & $21 \pm 1$ & $5 \pm 1$ & $24 \pm 1$ & $38 \pm 1$ & $3.3 \pm 0.3$ & $35 \pm 1$ & $24.6 \pm 0.3$ & $41 \pm 1$ \\
\hline & & 126 & $23 \pm 1$ & $3.6 \pm 0.3$ & $15 \pm 1$ & $43 \pm 1$ & $4.5 \pm 0.3$ & $38 \pm 1$ & $15.4 \pm 0.3$ & $47 \pm 1$ \\
\hline & & 153 & $21 \pm 1$ & $5 \pm 1$ & $11 \pm 1$ & $45 \pm 1$ & $5.9 \pm 0.3$ & $36.4 \pm 0.5$ & $12.6 \pm 0.2$ & $51 \pm 1$ \\
\hline \multirow[t]{2}{*}{ V } & \multirow{2}{*}{5} & 0 & $19 \pm 1$ & $3 \pm 1$ & $31 \pm 1$ & $37 \pm 1$ & $3.3 \pm 0.3$ & $30 \pm 1$ & $30.7 \pm 0.3$ & $39 \pm 1$ \\
\hline & & 126 & $17 \pm 1$ & $1.7 \pm 0.2$ & $15 \pm 1$ & $55 \pm 1$ & $6.1 \pm 0.3$ & $25 \pm 1$ & $15.7 \pm 0.2$ & $60 \pm 1$ \\
\hline \multirow[t]{5}{*}{$\mathrm{C}$} & \multirow{3}{*}{5} & 0 & $19 \pm 1$ & $2.5 \pm 0.2$ & $15 \pm 1$ & $52 \pm 1$ & $5.4 \pm 0.3$ & $28 \pm 1$ & $15.7 \pm 0.3$ & $56.0 \pm 0.3$ \\
\hline & & 126 & $20 \pm 1$ & $2.4 \pm 0.1$ & $9 \pm 1$ & $54 \pm 1$ & $6.5 \pm 0.3$ & $30 \pm 1$ & $10.0 \pm 0.4$ & $60 \pm 1$ \\
\hline & & 210 & $19 \pm 1$ & $2.4 \pm 0.1$ & $10.1 \pm 0.2$ & $53 \pm 1$ & $5.9 \pm 0.3$ & $30 \pm 1$ & $11.6 \pm 0.2$ & $58 \pm 1$ \\
\hline & \multirow[t]{2}{*}{25} & 0 & $19 \pm 1$ & $2.5 \pm 0.2$ & $15 \pm 1$ & $52 \pm 1$ & $5.4 \pm 0.3$ & $28 \pm 1$ & $15.7 \pm 0.3$ & $56.0 \pm 0.3$ \\
\hline & & 126 & $23 \pm 1$ & $3.3 \pm 0.3$ & $15 \pm 1$ & $45 \pm 1$ & $5.6 \pm 0.3$ & $35 \pm 1$ & $16.1 \pm 0.1$ & $49 \pm 1$ \\
\hline
\end{tabular}




\begin{tabular}{|c|c|c|c|c|c|c|c|c|c|}
\hline & 139 & $20 \pm 1$ & $1.9 \pm 0.1$ & $16 \pm 1$ & $48 \pm 1$ & $5.9 \pm 0.3$ & $30 \pm 1$ & $17.4 \pm 0.1$ & $53 \pm 1$ \\
\hline \multirow{5}{*}{$\begin{array}{l}\mathrm{p} \text { values at } \\
95 \% \\
\text { confidence } \\
\text { level }\end{array}$} & $\mathrm{T}$ & $<0.001$ & $<0.001$ & $<0.001$ & $<0.001$ & 0.054 & $<0.001$ & $<0.001$ & $<0.001$ \\
\hline & $\mathrm{G}$ & $<0.001$ & $<0.001$ & $<0.001$ & $<0.001$ & $<0.001$ & $<0.001$ & $<0.001$ & $<0.001$ \\
\hline & $\mathrm{T} \times \mathrm{G}$ & 0.001 & $<0.001$ & $<0.001$ & $<0.001$ & $<0.001$ & $<0.001$ & $<0.001$ & $<0.001$ \\
\hline & ST x G & $<0.001$ & $<0.001$ & $<0.001$ & $<0.001$ & $<0.001$ & $<0.001$ & $<0.001$ & $<0.001$ \\
\hline & T x ST x G & $<0.001$ & 0.005 & $<0.001$ & $<0.001$ & $<0.001$ & $<0.001$ & $<0.001$ & $<0.001$ \\
\hline
\end{tabular}

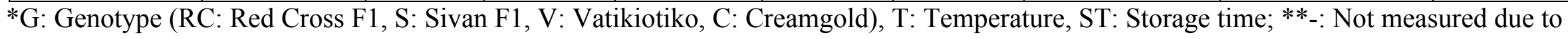
early sprouting. 
Table 7. Antioxidant properties of the studied onion samples (mean \pm SD) in relation to storage time (days) and storage temperature $(5$ and 25

$\left.{ }^{\circ} \mathrm{C}\right)$.

\begin{tabular}{|c|c|c|c|c|c|c|c|c|}
\hline & & & & & EC $_{50}$ values (m & $/ \mathrm{mL})$ & & \\
\hline $\mathrm{G}^{*}$ & $\begin{array}{l}\mathrm{T}^{*} \\
\left({ }^{\circ} \mathrm{C}\right)\end{array}$ & ST* (Days) & $\begin{array}{l}\text { Folin-Ciocalteu assay } \\
\text { (mg GAE/g extract) }\end{array}$ & $\begin{array}{l}\text { Flavonoids } \\
\text { (mg CE/g } \\
\text { extract) }\end{array}$ & $\begin{array}{l}\text { DPPH radical- } \\
\text { scavenging } \\
\text { activity }\end{array}$ & $\begin{array}{l}\text { Reducing } \\
\text { power }\end{array}$ & $\begin{array}{l}\beta \text {-carotene } \\
\text { bleaching } \\
\text { inhibition }\end{array}$ & $\begin{array}{l}\text { TBARS } \\
\text { inhibition }\end{array}$ \\
\hline \multirow{6}{*}{$\mathrm{RC}$} & \multirow{3}{*}{5} & 0 & $9.0 \pm 0.1$ & $0.1 \pm 0.1$ & $43.3 \pm 0.4$ & $2.3 \pm 0.2$ & $1.7 \pm 0.1$ & $10.0 \pm 0.3$ \\
\hline & & 126 & $12.9 \pm 0.1$ & $1.4 \pm 0.1$ & $19.3 \pm 0.2$ & $6.1 \pm 0.1$ & $4.5 \pm 0.1$ & $2.8 \pm 0.5$ \\
\hline & & 147 & $9.5 \pm 0.4$ & $1.4 \pm 0.4$ & $28.0 \pm 0.4$ & $7.8 \pm 0.1$ & $4.7 \pm 0.3$ & $3.3 \pm 0.1$ \\
\hline & \multirow[t]{3}{*}{25} & 0 & $9.0 \pm 0.1$ & $0.1 \pm 0.1$ & $43.3 \pm 0.4$ & $2.3 \pm 0.2$ & $1.7 \pm 0.1$ & $10.0 \pm 0.3$ \\
\hline & & 126 & $13.2 \pm 0.1$ & $1.5 \pm 0.1$ & $16.9 \pm 0.3$ & $5.7 \pm 0.1$ & $1.4 \pm 0.1$ & $1.9 \pm 0.3$ \\
\hline & & $-* *$ & - & - & - & - & - & - \\
\hline \multirow{6}{*}{$\mathrm{S}$} & \multirow{3}{*}{5} & 0 & $26.0 \pm 0.5$ & $0.2 \pm 0.1$ & $10.2 \pm 0.5$ & $1.3 \pm 0.01$ & $0.9 \pm 0.2$ & $6.9 \pm 0.5$ \\
\hline & & 126 & $9.6 \pm 0.1$ & $0.5 \pm 0.1$ & $52.1 \pm 0.3$ & $18.3 \pm 0.2$ & $1.8 \pm 0.1$ & $3.6 \pm 0.1$ \\
\hline & & 182 & $10.0 \pm 0.4$ & $0.6 \pm 0.1$ & $39.6 \pm 0.2$ & $11.4 \pm 0.1$ & $1.7 \pm 0.1$ & $2.5 \pm 0.1$ \\
\hline & \multirow[t]{3}{*}{25} & 0 & $26.0 \pm 0.5$ & $0.2 \pm 0.1$ & $10.2 \pm 0.5$ & $1.3 \pm 0.1$ & $0.9 \pm 0.2$ & $6.9 \pm 0.5$ \\
\hline & & 126 & $9.7 \pm 0.2$ & $0.7 \pm 0.2$ & $26 \pm 1$ & $8.4 \pm 0.1$ & $1.6 \pm 0.1$ & $2.2 \pm 0.1$ \\
\hline & & 153 & $9.5 \pm 0.4$ & $0.2 \pm 0.01$ & $32 \pm 1$ & $10.8 \pm 0.2$ & $2.1 \pm 0.1$ & $2.1 \pm 0.2$ \\
\hline \multirow{6}{*}{ V } & \multirow{3}{*}{5} & 0 & $8.0 \pm 0.1$ & nd & $44 \pm 1$ & $3.8 \pm 0.2$ & $1.1 \pm 0.2$ & $32 \pm 1$ \\
\hline & & 126 & $6.9 \pm 0.4$ & $0.3 \pm 0.1$ & $48 \pm 1$ & $14.0 \pm 0.1$ & $1.8 \pm 0.1$ & $3.7 \pm 0.2$ \\
\hline & & 210 & $6.7 \pm 0.1$ & $0.1 \pm 0.1$ & $57 \pm 1$ & $18.5 \pm 0.2$ & $4.9 \pm 0.3$ & $4.0 \pm 0.1$ \\
\hline & \multirow[t]{3}{*}{25} & 0 & $8.0 \pm 0.1$ & nd & $44 \pm 1$ & $3.8 \pm 0.2$ & $1.1 \pm 0.2$ & $32 \pm 1$ \\
\hline & & 126 & $6.9 \pm 0.1$ & $0.2 \pm 0.1$ & $49 \pm 1$ & $14.1 \pm 0.1$ & $2.2 \pm 0.1$ & $3.8 \pm 0.2$ \\
\hline & & 210 & $6.8 \pm 0.1$ & $0.2 \pm 0.1$ & $55 \pm 1$ & $13.9 \pm 0.1$ & $3.3 \pm 0.2$ & $2.3 \pm 0.1$ \\
\hline \multirow{3}{*}{$\mathrm{C}$} & \multirow{3}{*}{5} & 0 & $10.0 \pm 0.2$ & $0.1 \pm 0.1$ & $15.1 \pm 0.5$ & $3.9 \pm 0.1$ & $4.6 \pm 0.4$ & $32 \pm 1$ \\
\hline & & 126 & $8.3 \pm 0.1$ & $0.2 \pm 0.1$ & $37.4 \pm 0.3$ & $9.5 \pm 0.2$ & $3.0 \pm 0.1$ & $2.1 \pm 0.1$ \\
\hline & & 210 & $8.2 \pm 0.1$ & $0.3 \pm 0.1$ & $41 \pm 1$ & $12.5 \pm 0.1$ & $3.7 \pm 0.1$ & $2.3 \pm 0.1$ \\
\hline
\end{tabular}




\begin{tabular}{|c|c|c|c|c|c|c|c|}
\hline \multirow[t]{3}{*}{25} & 0 & $10.0 \pm 0.2$ & $0.1 \pm 0.1$ & $15.1 \pm 0.5$ & $3.9 \pm 0.5$ & $4.6 \pm 0.4$ & $32 \pm 1$ \\
\hline & 126 & $9.5 \pm 0.1$ & $0.2 \pm 0.1$ & $42 \pm 1$ & $9.1 \pm 0.4$ & $2.8 \pm 0.4$ & $2.1 \pm 0.1$ \\
\hline & 139 & $8.2 \pm 0.1$ & $0.2 \pm 0.1$ & $38 \pm 1$ & $12.3 \pm 0.1$ & $3.3 \pm 0.1$ & $2.1 \pm 0.1$ \\
\hline \multirow{7}{*}{$\begin{array}{l}\mathrm{p} \text { values at } 95 \% \\
\text { confidence level }\end{array}$} & $\mathrm{T}$ & $<0.001$ & $<0.001$ & $<0.001$ & $<0.001$ & 0.008 & $<0.001$ \\
\hline & ST & $<0.001$ & $<0.001$ & $<0.001$ & $<0.001$ & $<0.001$ & $<0.001$ \\
\hline & $\mathrm{G}$ & $<0.001$ & $<0.001$ & $<0.001$ & $<0.001$ & $<0.001$ & $<0.001$ \\
\hline & $\mathrm{T} \times \mathrm{ST}$ & $<0.001$ & $<0.001$ & $<0.001$ & 0.003 & $<0.001$ & $<0.001$ \\
\hline & $\mathrm{T} \times \mathrm{G}$ & $<0.001$ & $<0.001$ & $<0.001$ & $<0.001$ & 0.131 & $<0.001$ \\
\hline & ST x G & $<0.001$ & $<0.001$ & $<0.001$ & $<0.001$ & $<0.001$ & $<0.001$ \\
\hline & $\mathrm{T} \times \mathrm{ST} \times \mathrm{G}$ & $<0.001$ & $<0.001$ & $<0.001$ & 0.001 & $<0.001$ & $<0.001$ \\
\hline
\end{tabular}

GAE- gallic acid equivalents; $\mathrm{CE}$ - catechin equivalents. The results are presented in EC 50 values. what means that higher values correspond to

lower reducing power or antioxidant potential. $\mathrm{EC}_{50}$ : Extract concentration corresponding to $50 \%$ of antioxidant activity or 0.5 of absorbance for the reducing power assay.

*G: Genotype (RC: Red Cross F1, S: Sivan F1, V: Vatikiotiko, C: Creamgold), T: Temperature, ST: Storage time; **_: Not measured due to early sprouting. 


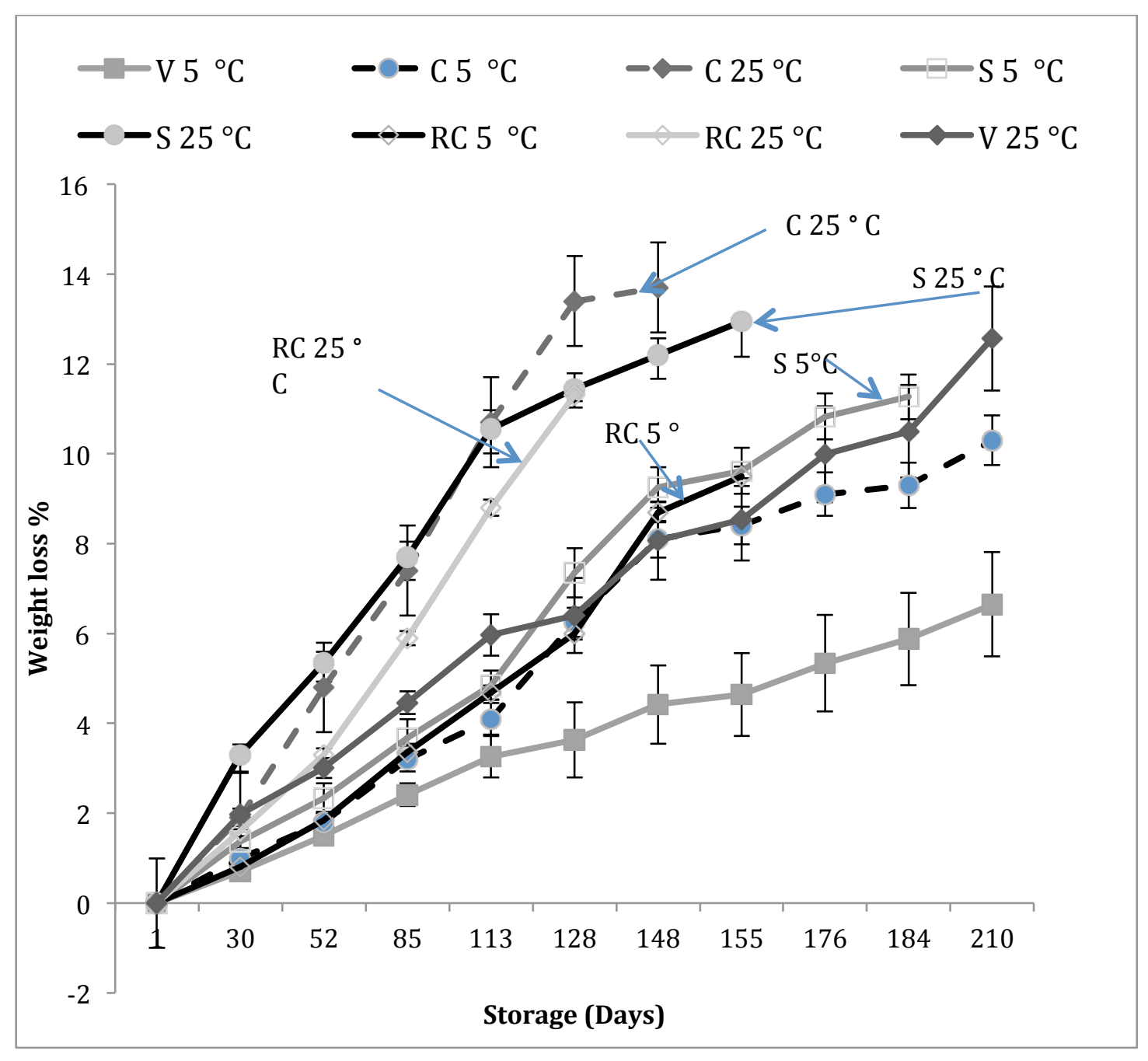

Figure 1. Weight loss (\% of the initial weight) in relation to storage time (days) of the studied genotypes (RC: Red Cross F1, S: Sivan F1, V: Vatikiotiko, C: Creamgold) at two temperatures $\left(5\right.$ and $\left.25^{\circ} \mathrm{C}\right)$. Arrows indicate the final sample taken before 210 days of storage. 

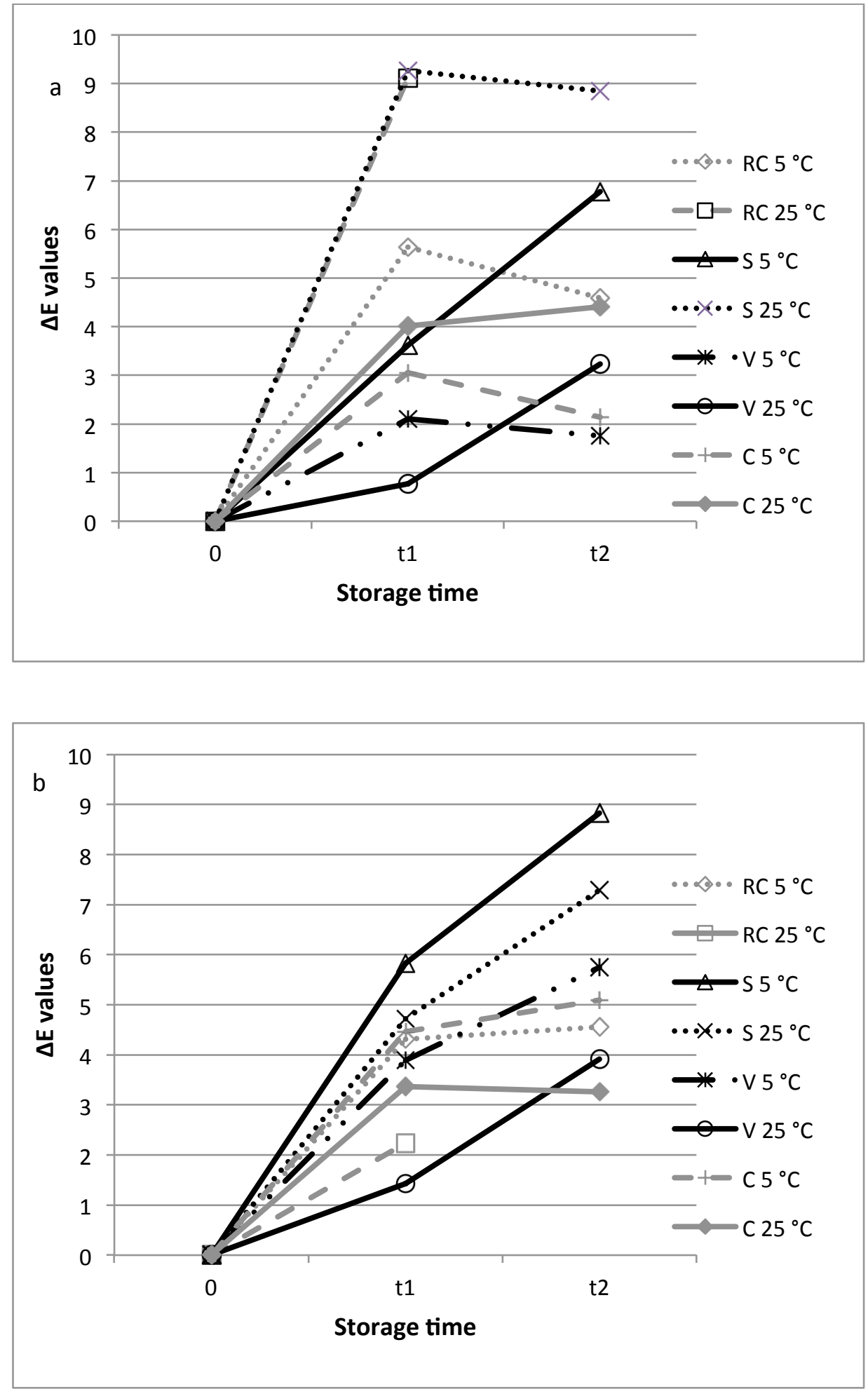

Figure 2. Total color difference values $(\Delta \mathrm{E})$ of tunic (a) and flesh (b) of onion bulbs of four genotypes (RC: Red Cross F1, S: Sivan F1, V: Vatikiotiko, C: Creamgold) in relation to storage time (days) at two different temperatures $\left(5\right.$ and $\left.25^{\circ} \mathrm{C}\right)$. 


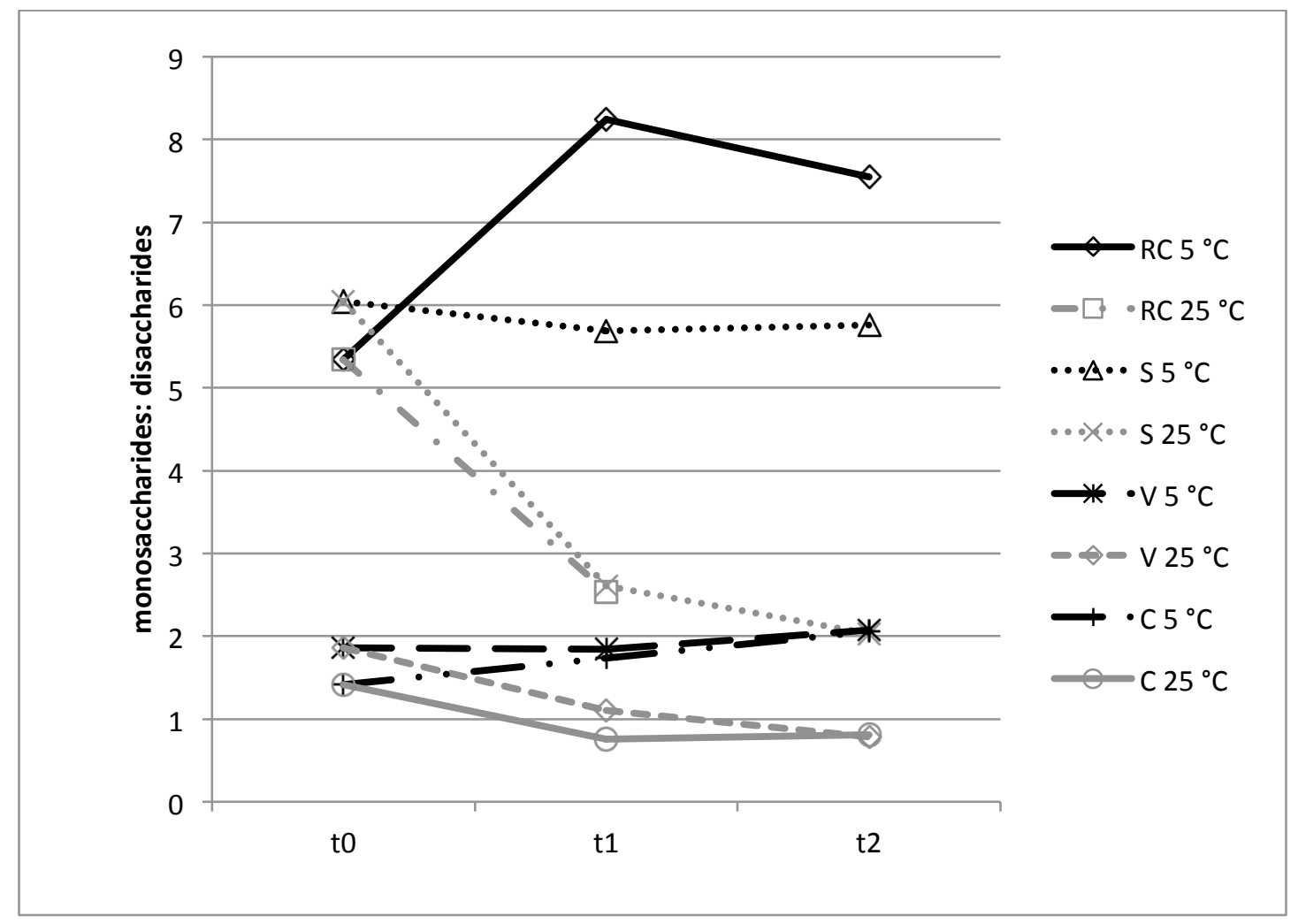

Figure 3. Monosaccharides: disaccharides ratio in relation to storage duration ( $\mathrm{t} 0, \mathrm{t} 1$ and t2) and storage temperature (5 and $\left.25^{\circ} \mathrm{C}\right)$. (RC: Red Cross F1, S: Sivan F1, V: Vatikiotiko, C: Creamgold). 


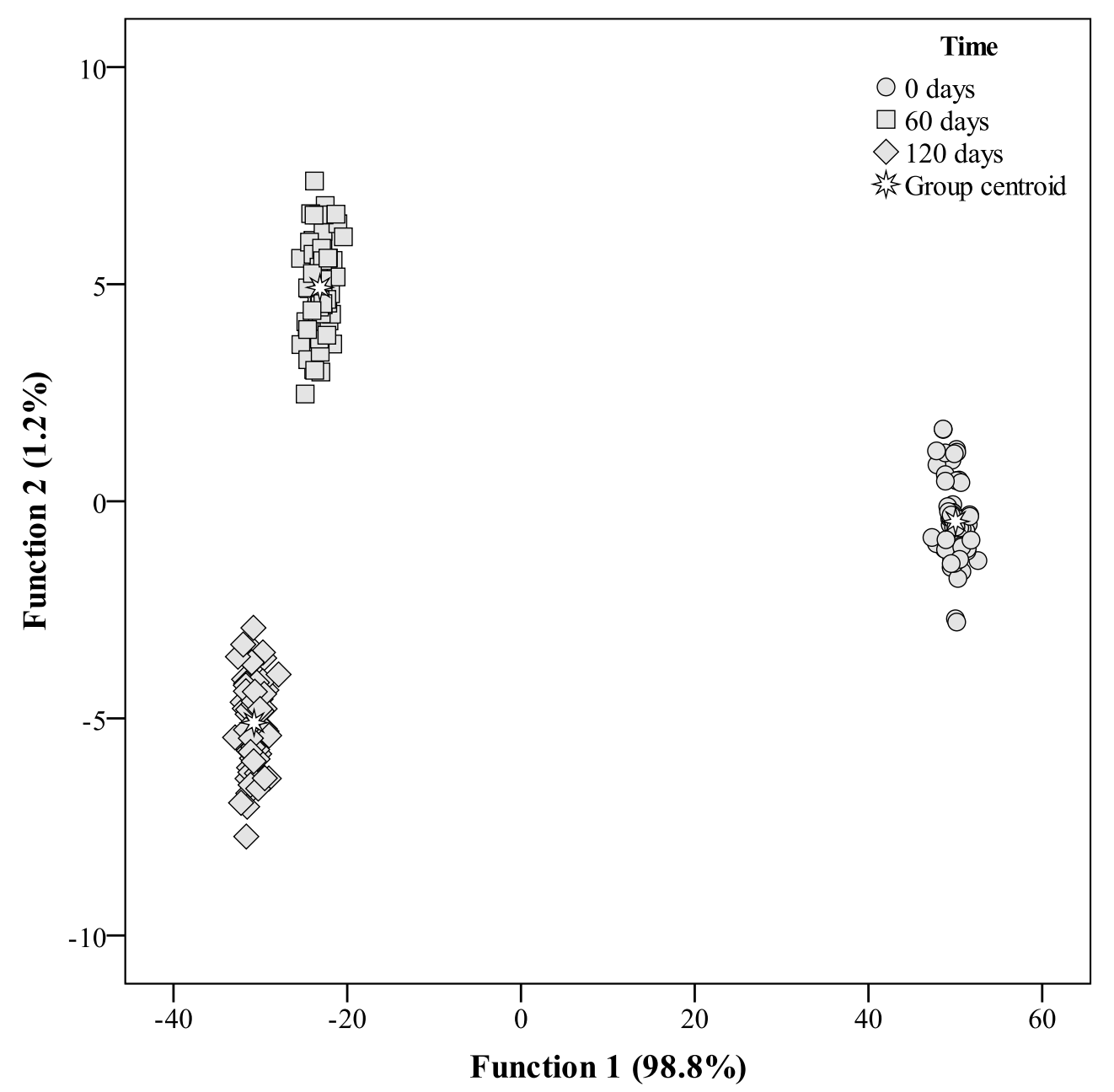

Figure 4. Canonical discriminant functions coefficients defined from the evaluated parameters plotted to show the effect of storage time in onion samples from different cultivars and stored under different temperatures. 


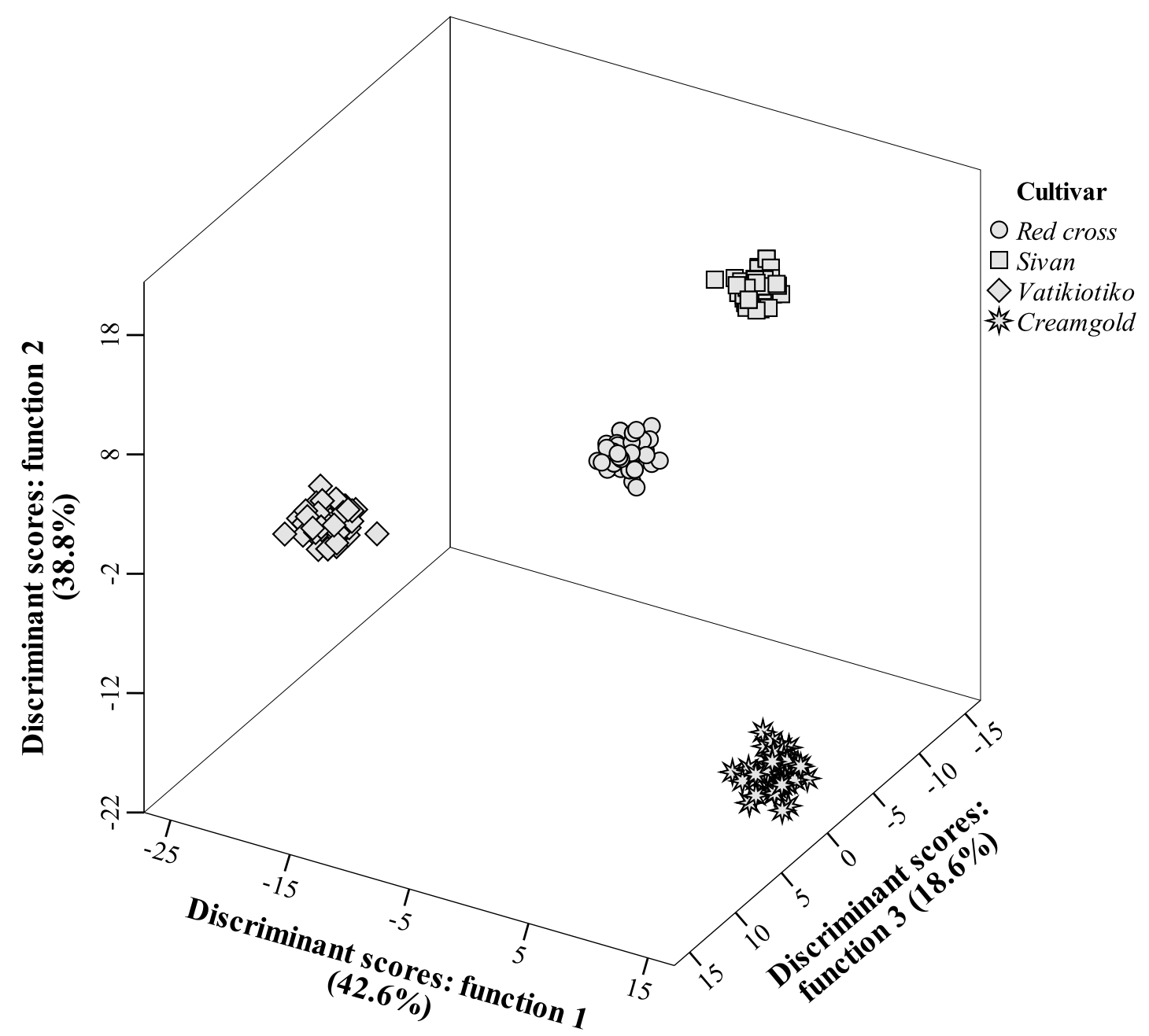

Figure 5. Canonical discriminant functions coefficients defined from the evaluated parameters plotted to show the effect of onion cultivar in samples stored under different temperatures and storage times. 